OAK RIDGE NATIONAL LABORATORY

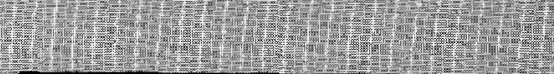

MARTIN MARIETTA

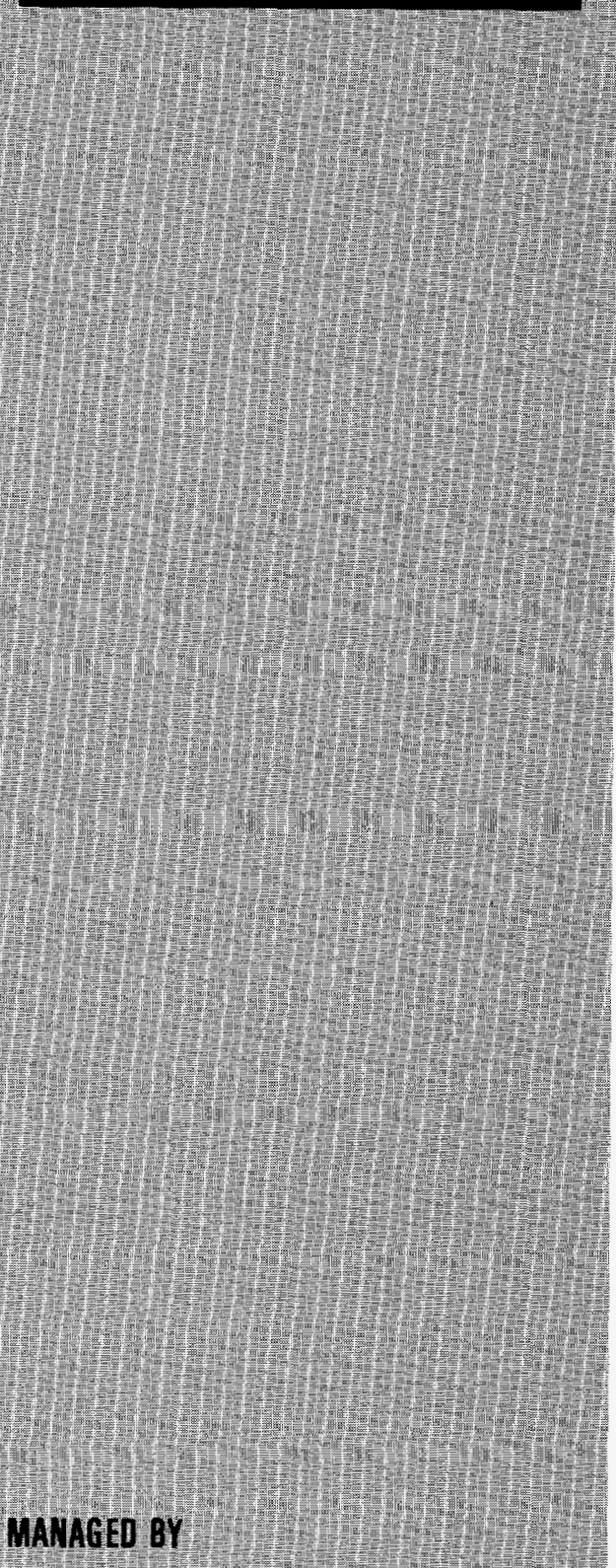

MARTIN MARIETIA EMERGY SYSTEUS, IIC.

FOR THE UNITED STATES

DEPARTMENT OF ENERGY

\section{Aggregate Vehicle Travel Forecasting Model}

\author{
David L. Greene \\ Shih-Miao Chin \\ Robert Gibson
}


This report has been reproduced directly from the best available copy.

Available to DOE and DOE contractors from the Office of Scientific and Technical Information, P.O. Box 62, Oak Ridge, TN 37831; prices available from (615) 576-8401, FTS 626-8401.

Available to the public from the National Technical information Service, U.S. Department of Commerce, 5285 Port Royal Rd., Springfield, VA 22161.

This report was prepared as an account of work sponsored by an agency of the United States Government. Neither the United States Government nor any agency thereof, nor any of their employees, makes any warranty, express or implied, or assumes any legal liability or responsibility for the accuracy, completeness, or usefulness of any information, apparatus, product, or process disclosed, or represents that its use would not infringe privately owned rights. Reference herein to any specific commercial product, process, or service by trade name, trademark, manufacturer, or otherwise, does not necessarily constitute or imply its endorsement, recommendation, or favoring by the United States Government or any agency thereof. The views and opinions of authors expressed herein do not necessarily state or reflect those of the United States Government or any agency thereof. 


\section{DISCLAIMER}

Portions of this document may be illegible in electronic image products. Images are produced from the best available original document. 
This report has been reproduced directly from the best available copy.

Available to DOE and DOE contractors from the Office of Scientific and Technical Information, P.O. Box 62, Oak Ridge, TN 37831; telephone (615) 576-8401 for prices.

Available to the public from the National Technical Information Service, 5285 Port Royal Road, Springfield. VA 22161.

Copies of this document are available (while supplies last) upon written request to:

Office of Fissile Materials Disposition, MD-4 (EIS IP) Forrestal Building United States Department of Energy 1000 Independence Avenue, SW Washington, DC 20585 


\section{Department of Energy \\ Washington, DC 20585}

\section{JUN 301995}

Dear Interested Party:

On April 5, 1995, the Department of Energy issued a Notice of Intent (NOI) to prepare an Environmental Impact Statement (EIS) on the disposition of surplus highly enriched uranium (HEU). Scoping for HEU disposition occurred as part of the scoping process for the Long-Term Storage and Disposition of Weapons-Usable Fissile Materials Programmatic Environmental Impact Statement held between August and October 1994.

Enclosed for your information is a copy of the Implementation Plan that will be used as guidance by the Department in the preparation of the EIS. The Implementation Plan also contains a list of issues that were raised during the scoping process and identifies how each issue will be considered in the EIS.

The Department presently plans to issue the Draft EIS in August 1995. Following a public comment period, which will include public meetings in September 1995, the Final EIS and the Record of Decision will be issued in early 1996.

If you have any questions regarding the Implementation Plan or preparation of the EIS, please contact the Office of Fissile Materials Disposition at (202) 586-4513 or write to:

Mr. J. David Nulton

Office of Fissile Materials Disposition, MD-4

Forrestal Building

U.S. Department of Energy

1000 Independence Avenue, S.W.

Washington, D.C. 20585

The Department looks forward to continued public interest and participation in this program.

Sincerely,

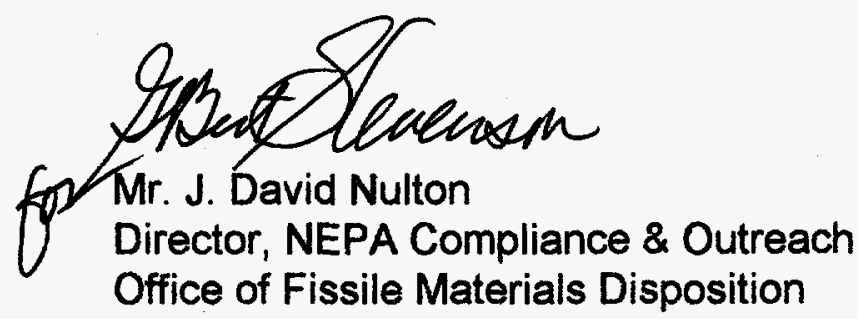

Enclosure 
Aggregate Vehicle Travel Forecasting Model

\author{
David L. Greene \\ Shih-Miao Chin \\ Center for Transportation Analysis \\ Robert Gibson \\ University of Tennessee \\ Knoxville, Tennessee
}

May 1995

Research sponsored by

Office of Policy Development

Federal Highway Administration

U. S. Department of Transportation

Washington, DC 20590

\author{
Prepared by the \\ Oak Ridge National Laboratory \\ Oak Ridge, Tennessee 37831-6207 \\ managed by \\ MARTIN MARIETTA ENERGY SYSTEMS, INC. \\ for the \\ U. S. DEPARTMENT OF ENERGY \\ under contract DE-AC05-84OR21400
}



TABLE OF CONTENTS

LIST OF FIGURES $\ldots \ldots \ldots \ldots \ldots \ldots \ldots \ldots \ldots \ldots \ldots \ldots \ldots \ldots \ldots \ldots \ldots$

LIST OF TABLES $\ldots \ldots \ldots \ldots \ldots \ldots \ldots \ldots \ldots \ldots \ldots \ldots \ldots \ldots \ldots \ldots$

ABSTRACT $\ldots \ldots \ldots \ldots \ldots \ldots \ldots \ldots \ldots \ldots \ldots \ldots \ldots \ldots \ldots \ldots \ldots \ldots \ldots \ldots \ldots \ldots$

ACKNOWLEDGMENTS $\ldots \ldots \ldots \ldots \ldots \ldots \ldots \ldots \ldots \ldots \ldots \ldots \ldots \ldots \ldots \ldots \ldots \ldots \ldots \ldots$

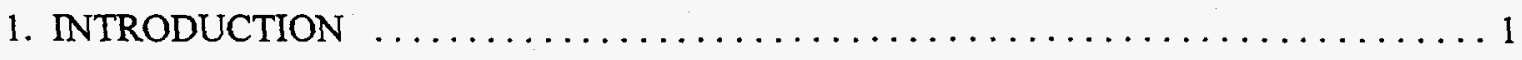

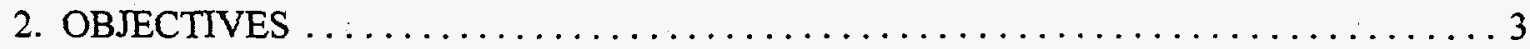

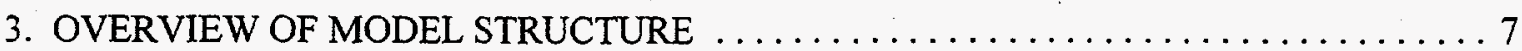

4. SHORT-TERM VMT FORECASTING MODULE $\ldots \ldots \ldots \ldots \ldots \ldots \ldots \ldots \ldots$

5. SHORT-TERM FORECASTING MODEL EQUATIONS $\ldots \ldots \ldots \ldots \ldots \ldots \ldots \ldots$

5.1 PERSONAL USE VEHICLE VMT EQUATION $\ldots \ldots \ldots \ldots \ldots \ldots \ldots \ldots \ldots$

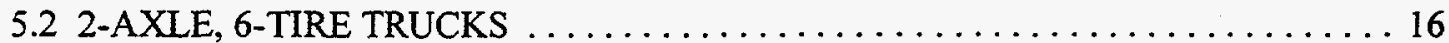

5.3 OTHER SINGLE UNIT TRUCK VMT $\ldots \ldots \ldots \ldots \ldots \ldots \ldots \ldots \ldots \ldots \ldots \ldots \ldots$

5.4 SINGLE-TRAILER COMBINATION TRUCK VMT $\ldots \ldots \ldots \ldots \ldots \ldots \ldots \ldots 21$

5.5 MULTIPLE-TRAILER COMBINATION TRUCK VMT $\ldots \ldots \ldots \ldots \ldots \ldots \ldots 21$

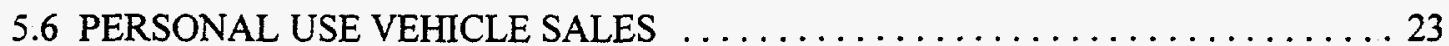

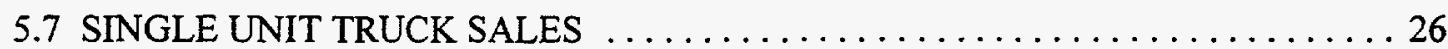

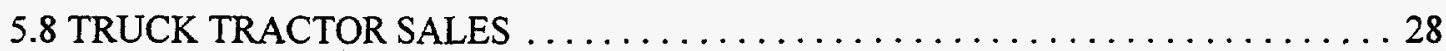

6. LONG-TERM VMT FORECASTING MODULE $\ldots \ldots \ldots \ldots \ldots \ldots \ldots \ldots \ldots \ldots \ldots \ldots \ldots$

6.1 PASSENGER VEHICLE TRAVEL MODEL DESIGN $\ldots \ldots \ldots \ldots \ldots \ldots \ldots \ldots$

6.2 FREIGHT VEHICLE TRAVEL MODEL DESIGN $\ldots \ldots \ldots \ldots \ldots \ldots \ldots \ldots$

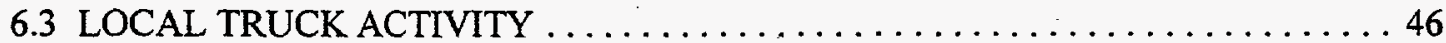

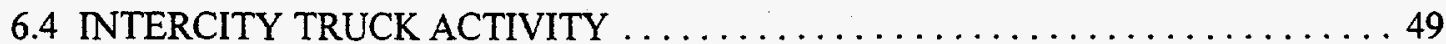

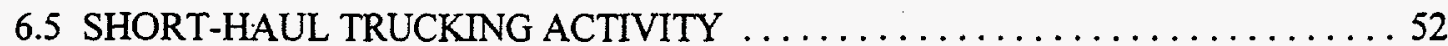

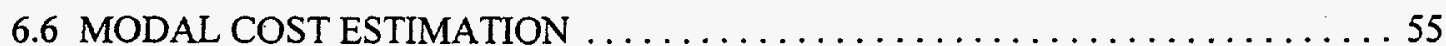

7. SYSTEM DESIGN AND DOCUMENTATION $\ldots \ldots \ldots \ldots \ldots \ldots \ldots \ldots \ldots \ldots \ldots \ldots \ldots \ldots \ldots$

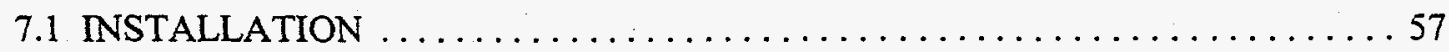

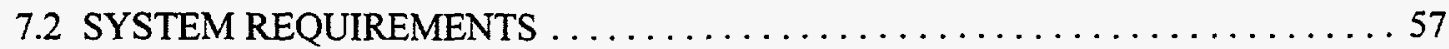

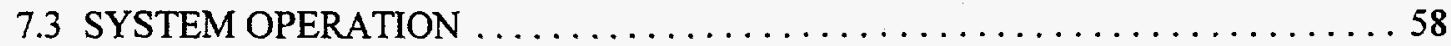

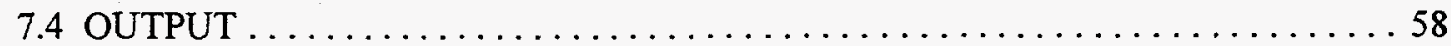

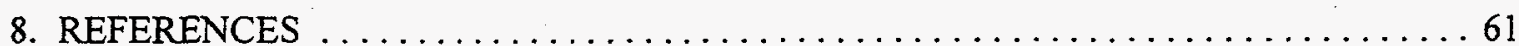





\section{LIST OF FIGURES}

Figure 1. Aggregate VMT Forecasting Software Structure $\ldots \ldots \ldots \ldots \ldots \ldots \ldots$

Figure 2. Aggregate VMT Forecasting Model Structure $\ldots \ldots \ldots \ldots \ldots \ldots \ldots \ldots$

Figure 3. Personal Use Vehicle Travel Regression Model $\ldots \ldots \ldots \ldots \ldots \ldots \ldots \ldots \ldots 17$

Figure 4. 2-Axle, 6-Tire Single Unit Truck Travel Regression Model . . . . . . . . . . 19

Figure 5. Other Single Unit Truck Travel Regression Model $\ldots \ldots \ldots \ldots \ldots \ldots \ldots \ldots \ldots$

Figure 6. Single Trailer Combination Truck Travel Regression Model . . . . . . . . . 22

Figure 7. Multiple Trailer Combination Truck Travel Regression Model . . . . . . . 24

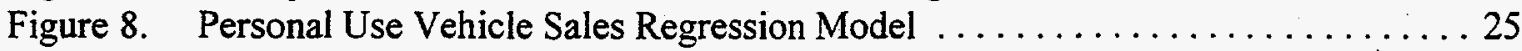

Figure 9. Single Unit Truck Sales Regression Model $\ldots \ldots \ldots \ldots \ldots \ldots \ldots \ldots \ldots \ldots \ldots$

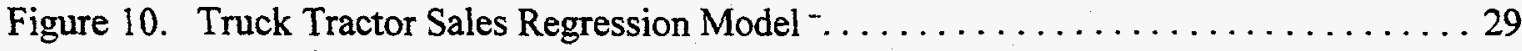

Figure 11. Licensed Drivers, 1991, Distributed by Sex and Age .............. 36

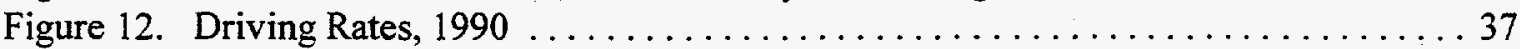

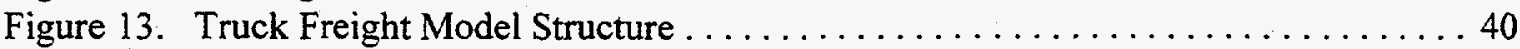

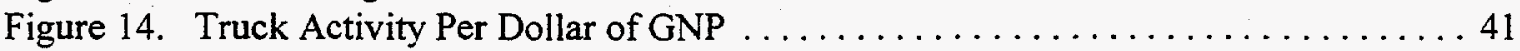

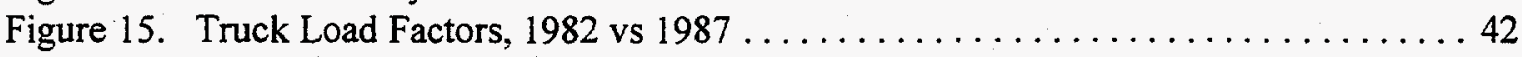

Figure 16. Intercity Ton-Miles, Time Trend in Ton-Miles / $1987 \$$ of GNP . . . . . . . 45

Figure 17. Distribution of Ton-Miles, 1982, by Truck Type and Length of Haul . . . . . 47

Figure 18. Distribution of Ton-Miles, 1987, by Truck Type and Length of Haul . . . . . 47

Figure 19. Distribution of Vehicle-Miles, 1982, by Truck Type and Length of Haul . . . . 48

Figure 20. Distribution of Vehicle-Miles, 1987, by Truck Type and Length of Haul . . . . 48

Figure 21. Distribution of Short-Haul Ton-Miles, Actual versus Average of

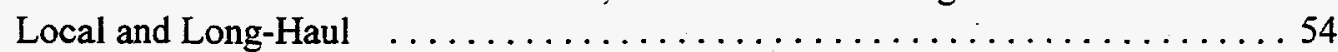

\section{LIST OF TABLES}

Table 1. Local Ton-Miles and Vehicle Miles Relative to GNP and Intercity Miles . . . . 43 



\begin{abstract}
This report describes a model for forecasting total U.S. highway travel by all vehicle types, and its implementation in the form of a personal computer program. The model comprises a short-run, econometrically-based module for forecasting through the year 2000 , as well as a structural, scenario-based longer term module for forecasting through 2030 . The short-term module is driven primarily by economic variables. It includes a detailed vehicle stock model and permits the estimation of fuel use as well as vehicle travel. The longer-term module depends on demographic factors to a greater extent, but also on trends in key parameters such as vehicle load factors, and the dematerialization of GNP. Both passenger and freight vehicle movements are accounted for in both modules. The model has been implemented as a compiled program in the Fox-Pro database management system operating in the Windows environment.
\end{abstract}





\section{ACKNOWLEDGMENTS}

The authors wish to thank Jim March and Gary Maring for their interest and support, as well as Frank Southworth and Shaw-Pin Miaou for comments on an earlier draft. Any remaining errors are the author's responsibility. This report is dedicated to Michael Greene. 


\section{INTRODUCTION}

At a microscopic scale, the factors influencing vehicle travel (VMT) appear to be infinitely complex. Nearly every aspect of household demographics and lifecycle stages have been shown to influence travel behavior, plus the specific structure of the spatial environment, land use, vehicle availability, time-of-day variations in travel volumes and level of service, the availability and characteristics of alternatives, and, of course, individual values and life-style (Kitamura, 1988; Reno, 1988). At the macroscopic level, however, the growth of vehicle travel appears to be quite regular and readily predictable with simple models. No more than three or four variables are required for an econometric model of light duty vehicle-miles that statistically explains $99.5 \%$ of the historical variability of VMT.' Thus, total national vehicle travel, despite or perhaps because of the fact that it is composed of billions of individual decisions of infinite complexity, is relatively easily forecasted with a few simple independent variables.

Econometric models of vehicle travel essentially extrapolate past relationships and trends into the future. The history of highway travel is one of rapid expansion to a position of dominance in the U.S. transportation system. Now that the highway infrastructure is mature and the economic geography of the nation has evolved in concert with it, now that there is more than one motor vehicle for every licensed driver, it is probably no longer reasonable to simply extrapolate past econometric relationships into the long-term future. Though statistical models based on historical data are probably best for projecting a few years into the future, they are likely to overstate the effect of economic growth on highway travel for both passengers and freight. Since the Federal Highway Administration (FHWA) needs both short- and long-term forecasts of highway travel, alternative, robust methods are needed for longer-term forecasting ( 5 to 50 years).

The new aggregate VMT model combines econometric equations for short-term forecasting with a structured approach to scenario building for longer-term projections. Both are sensitive to changes in key policy variables, such as tax rates. The longer-term forecasting methodology, however, permits assumptions about key parameters to be explicitly changed to create alternative future scenarios and allows a greater variety of policy variables to be explicitly included. Factors such as

\footnotetext{
'A recent study by Greene (1992) indicates that an annual equation for national light duty vehicle travel may include: 1) the number of licensed drivers, 2) the fuel cost per mile of travel, and 3) either income (or GNP) or the number of vehicles in operation, but not both.
} 
licensing rates by demographic group, vehicle occupancy rates, and highway miles per driver may be extrapolated based on past trends, or new trends may be defined. On the freight side, factors such as tons shipped per dollar of GNP, load factors, or the relationship of modal shares in short- and long-haul traffic can be altered to create scenarios. By and large, the parameters of the longer-term forecasting models are not estimated directly from time series, but are based on the consensus of the extant literature and on the judgment of the analyst. 


\section{OBJECTIVES}

FHWA has seven principal objectives for the Highway VMT Forecasting Model:

1. accuracy of forecasts of future vehicle travel,

2. sensitivity to alternative policy assumptions,

3. ability to produce scenarios based on various assumptions about trends in critical but hard-to-predict factors,

4. logical consistency and sound theoretical basis,

5. ease of use,

6. ease of maintenance and updating, and

7. consistency with other FHWA models with which it will interact.

FHWA is interested in both short-term and long-term forecasting of vehicle travel. Short-term forecasts, taking into account recent trends, are important to decisions about budgetary appropriations and authorizations, and for near-term projection of Highway Trust Fund revenues. Longer-term forecasts are important to formulating long-range planning for the highway system, and for evaluating the effects of policies that have their full impact only after several years. In this report, we intend "short-term" to mean a period of roughly 1 to 5 years in the future. Long-term forecasts mean 5 to 50 years into the future.

Two fundamental approaches to VMT forecasting were identified by Kirby (1981).

1. Search for constancy, in which the analyst, knowing his forecasts are based on assumptions about certain parameters being constant, seeks to find those things which appear constant.

2. A search for (understanding) variability, in which the analyst seeks to understand why things change as they do, and is essentially looking for explanations.

Underlying these two approaches are the competing objectives of accuracy in prediction and the ability to understand relationships by allowing various factors that have important impacts on VMT to influence the forecast. The relative importance of these two objectives differs for long-term versus short-term forecasting. For short-term forecasts, there is greater emphasis on the accuracy 
of the prediction. For longer-term forecasts, understanding the underlying causes and driving forces for change has greater emphasis.

By finding relationships that have remained constant over time, the analyst increases his chances of producing an accurate forecast, regardless of changes in other factors that may influence VMT but whose values or relationship to VMT may themselves be inherently unpredictable. Constant relationships, however, do not lend themselves to conditional ("what if") analyses that are essential for policy analysis. They aiso do not permit one to explore the consequences of plausible changes in the directions of historical trends. Thus, models ideally should be based on exogenous variables 1) that are predictable with a high degree of accuracy, 2) whose relationship to VMT may be varied by assumption to reflect plausible, alternative socioeconomic trends, and 3 ) that are relevant to a wide variety of possible public policies. Demographic variables, the size, geographical distribution, age distribution, and gender of the population, are all promising candidates. Economic output and prices, though less satisfactory in terms of predictability and constancy of relationship, are important for theoretical validity and for policy and scenario analysis.

The model should be useful for analyzing three broad categories of policies:

1. taxes on fuels, vehicles and components, and vehicle use;

2. regulations on vehicle size, weight, efficiency, and possibly safety and emissions; and

3. infrastructure supply, and especially its effects on congestion and level of service.

The model must reflect the impacts of policies on numerous factors such as vehicle sales and ownership (stock), vehicle use, intermodal competition, and fuel consumption, at least. In addition, it may be desirable to represent policies affecting the type of fuel used by the vehicle stock to be able to predict the impacts of alternative fuels policies. This and other considerations imply that a component of the VMT model must predict vehicle sales and survival rates by vehicle and fuel technology type as well as predict overall vehicle usage. A capital stock model is essential for forecasting trends that depend on changes in technology over time. Due to the inherent uncertainty in anticipating developments in vehicle technology over a period of 20-50 years, we have implemented a capital stock model for only short-term VMT forecasting.

Trends in the relationships between demographic, economic, and vehicle stock characteristics and VMT are difficult to predict based on inferences from historical data, but they can have a profound effect on the future growth of VMT. Critical trends include rates of vehicle use per male and female driver, vehicle occupancy trends, the potential for "saturation" effects in the relationships among income, vehicle ownership, and vehicle travel; the regional and intra-urban distribution of population and employment; and trends in the composition of economic output in terms of value and 
weight. The model allows for explicit changes in assumptions about such trends in a straightforward and clear manner.

Microeconomic travel theory, recognizing both income and time constraints, provides the theoretical basis for the model of personal vehicle travel (Golob, Beckmann, and Zahavi, 1981). Aggregate freight forecasting models are less common and are typically macroeconomic, based on empirical relationships between GNP or output by sector and ton-miles or vehicle-miles (Greene, 1984; Weinblatt, 1989; Apogee, 1990; Mintz and Vyas, 1991). ${ }^{2}$ It is possible, however, to derive freight demand from microeconomic theory, though such formulations are little used for aggregate forecasting (Winston, 1983). The longer term freight VMT model is driven by GNP but incorporates microeconomic detail in representing the competition among truck types and between truck and rail modes.

Ease of use is an important practical consideration for any model. The three basic functions of the model, input, model control, and output, are illustrated in Figure 1. The primary considerations regarding this subject include the following:

1. quantity of input required for creating a forecast,

2. availability of forecasts of key exogenous variables,

3. completeness and simplicity of documentation for the user, and

4. quality of the user interface for both input and output.

The VMT forecasting model is designed to operate on a 80386-CPU, 80486-CPU, or better microcomputer and utilizes a familiar, sophisticated interface: the Windows version of the FoxPro database management system. The entire model is contained within this single format.

The VMT forecasting model must interface with other FHWA Office of Policy Development models--in particular, the Highway Revenue Forecasting Model (Apogee, 1990) and the Highway Traffic Forecasting System (Southworth and Ray, 1993). Definitions of key variables such as vehicle class, have been made as compatible as possible given data availability and statistical considerations.

\footnotetext{
${ }^{2}$ Aggregate models are aspatial, in contrast with spatial interaction models of freight movements, which represent movements between specific geographical origins and destinations.
} 


\section{FIGURE 1. AGGREGATE VMT FORECASTING SOFTWARE STRUCTURE}

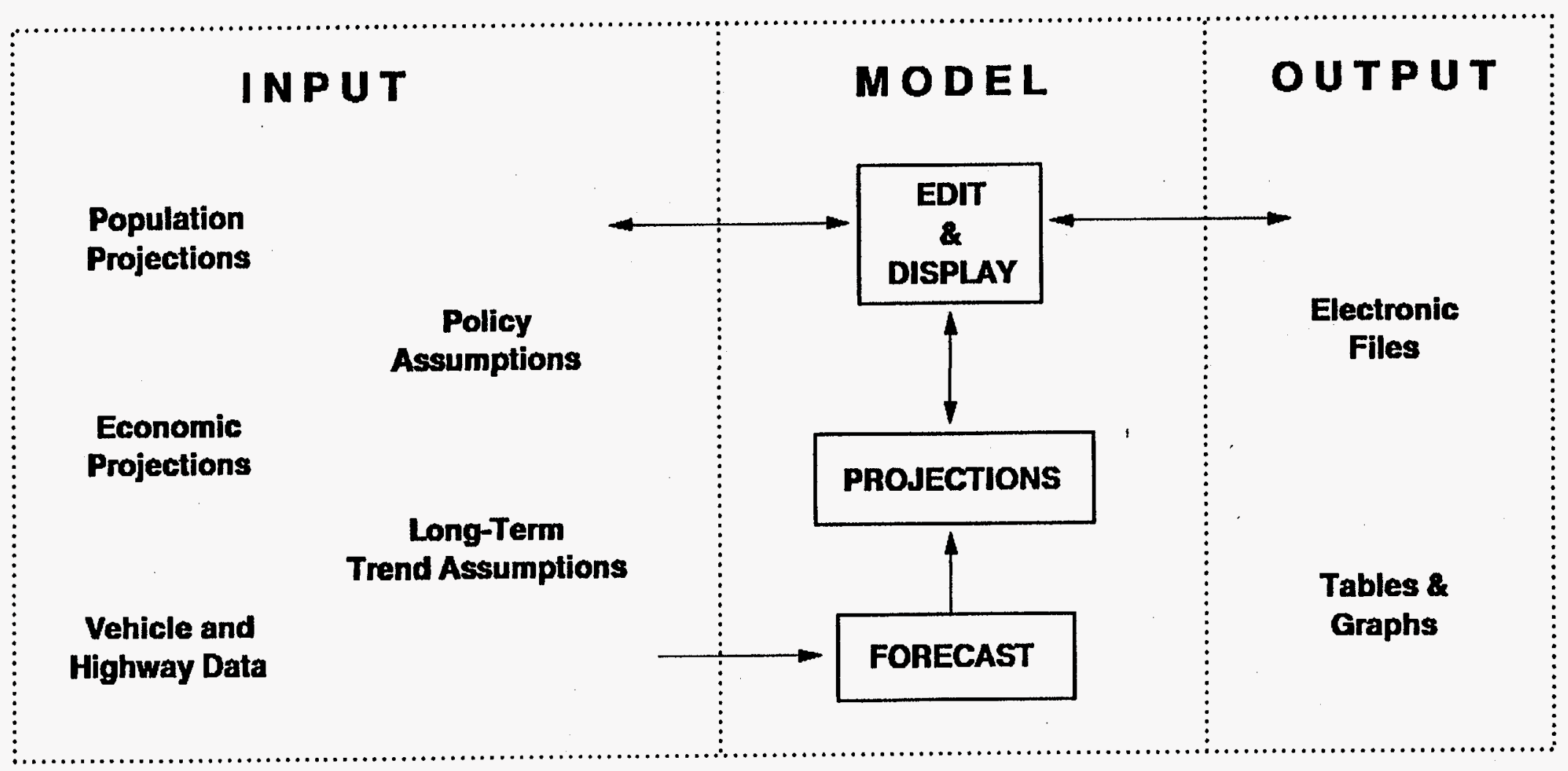




\section{OVERVIEW OF MODEL STRUCTURE}

The Aggregate VMT Forecasting Model consists of distinct short-term and long-term modules (Figure 2). The short-term model contains equations for five types of vehicles, for annual forecasting of vehicle miles of travel, vehicle sales, vehicle stocks, and fuel use. Stocks are derived by subtracting scrappage and adding sales to last year's stock. ${ }^{3}$ The short-term stock model allows the effects of market penetrations of alternative fuel vehicles to be explored. The longer-term module comprises structural models for the passenger and freight sectors. The same five vehicle types are represented but there is no stock model.

1. Short-term Module - forecasting annual VMT, vehicle stocks, and fuel use to the year 2000:

(a) Vehicle travel equations

(b) Vehicle sales and retirement equations

(c) Short-term stock model

2. Long-term Module - forecasting vehicle miles by highway vehicles by 5-year intervals to 2030 :

(a) Passenger VMT Model - for projecting vehicle travel by passenger cars and light trucks based primarily on demographic trends.

(b) Freight VMT Model - for projecting vehicle miles by larger single unit and combination trucks based on projected ton-miles, modal shares, and load factors.

Each module is described below.

${ }^{3}$ Twenty-five vehicle vintages are maintained. Limited availability and dubious accuracy of sales and stock data for the five truck types led us to combine all vehicles into three types: personal vehicies (passenger cars and light trucks), other single unit trucks, and truck tractors. 
FIGURE 2. AGGREGATE VMT FORECASTING MODEL STRUCTURE

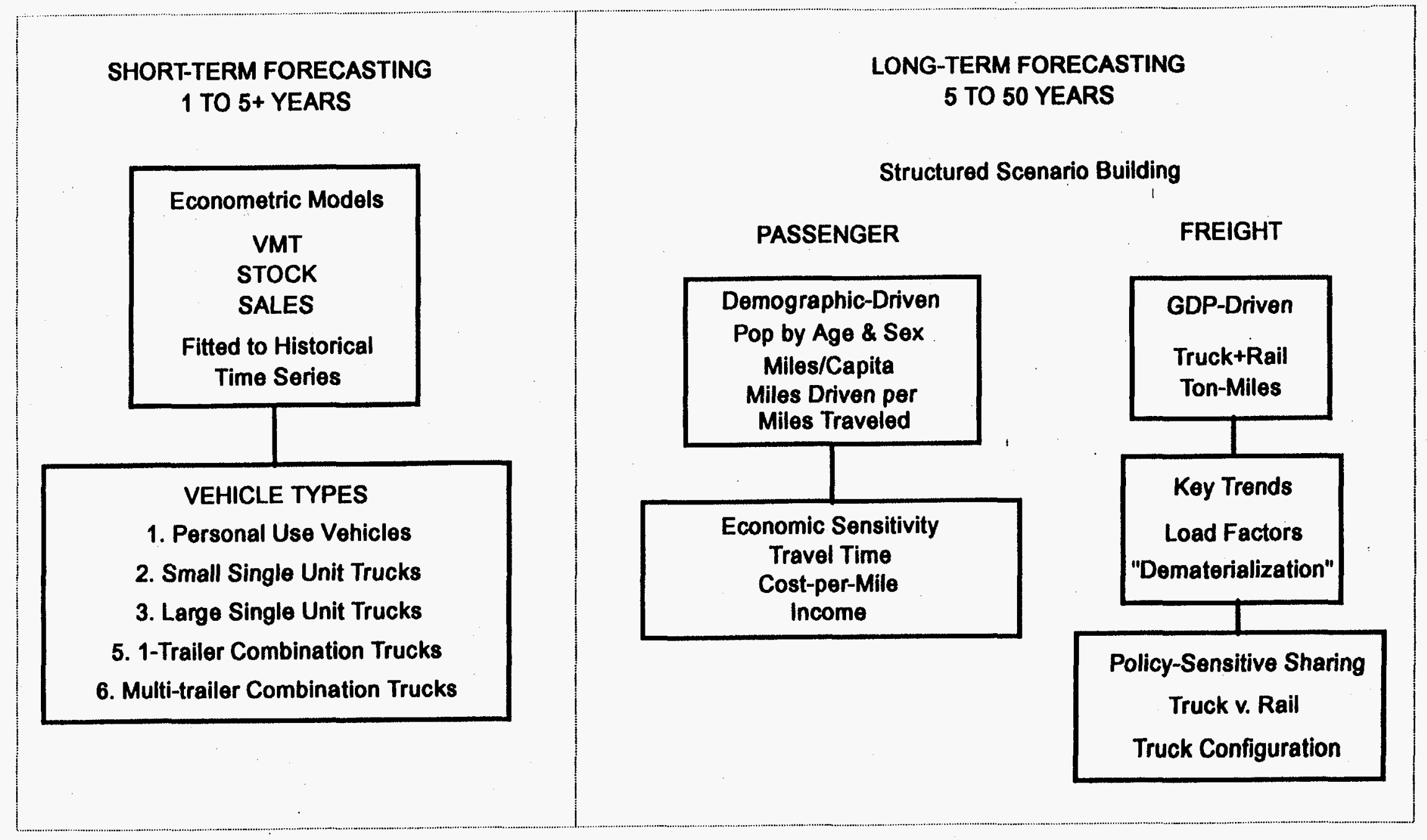




\section{SHORT-TERM VMT FORECASTING MODULE}

The primary objective of short-term forecasting is accuracy in the prediction of vehicle miles and related factors: fuel use, vehicle sales, and vehicle stocks. Another goal is assessment of the nearterm impacts of transportation policies, especially effects of changes on highway user revenues. Statistical methods which make use of the recent historical record are best suited to this task. The philosophy adopted here is that regression equations fitted to time series data permits the rigorous minimization of the expected error of the forecasts and allows quantification of the effects of key exogenous variables, such as income and fuel prices, on VMT. A disadvantage of the econometric approach is that the data can dictate which variables appear in forecast equations and which do not. Variables of policy interest may not be statistically significant. In the models estimated here, for example, vehicle prices were generally not statistically significant.

The short-term model consists of five forecasting equations used to predict vehicle travel for five types of vehicle:

1. passenger vehicles comprised of passenger cars and 2-axle, 4-tire trucks;

2. two-axle, 6-tire single-unit trucks;

3. other single unit trucks;

4. single-trailer combination trucks; and

5. multi-trailer combination trucks.

The general form of the short-term forecasting equations expresses the first difference of vehicle miles, the dependent variable ( $y$ ), as a function of contemporaneous exogenous variables, the lagged dependent variable, and differences of the exogenous variables. All variables are logarithms of their actual values.

$$
\Delta y_{t}=\rho\left(Y_{t}-y_{t-1}\right)+\sum_{k=1}^{n} b_{k} \Delta x_{k t}
$$

In equation (4.1), $Y_{t}$ represents the "desired" or "long-run" level of VMT, and $\rho$ is a partial adjustment parameter. The thrust of equation (4.1) is that the observed change in VMT $\left(\Delta \mathrm{y}_{t}\right)$ will be some fraction of the desired change $\left(Y_{t}-y_{t-1}\right)$. The terms involving differences in exogenous variables $\left(\Delta x_{\mathrm{kt}}\right)$ are intended to capture transitory dynamic effects. For example, a one-time but permanent change in the level of an exogenous variable $x_{k}$ would cause a change in $y$ via the 
variable $\Delta x_{k}$ only in the time period in which the change occurred. The effect through $\Delta x_{k}$ would disappear in the very next period. The effect via the lagged value of the dependent variable would decay over time according to the value of $\rho$. This type of time series model, known as an error correction model is now replacing traditional lagged adjustment models as the preferred method for modeling economic time series (Engle and Granger, 1987).

Desired VMT $\left(Y_{t}\right)$ is assumed to be a function of the current values of exogenous variables, so that $\Delta y_{t}$ is a function of these variables, as well.

$$
Y_{t}=\sum_{k=1}^{n} a_{k} x_{k t}
$$

By substituting $\left(Y_{t}\right)$ as defined in equation (4.2) into equation (4.1), it is easy to show that the coefficients of non-differenced exogenous variables are equal to $\rho a_{k}$. All variables are in logarithms, so that the coefficients represent short-run elasticities. Long-run elasticities may therefore be obtained by dividing by $\rho$, which will be the negative of the coefficient of the lagged dependent variable, $\mathrm{y}_{\mathrm{t}-\mathrm{-}}$. If equation (4.2) were linear, then the inclusion of a constant term on the right-handside would definitively imply that an exogenous trend was present, regardless of the units in which the exogenous variables are expressed. When all variables are in logarithms, the presence of a constant term may imply the existence of a trend or it may be required to account for the units in which the variables are expressed. This is because in the logarithmic model the constant is a multiplier of the product of exogenous variables, each raised to its own exponent (elasticity). In the statistical estimation of such equations, we will need to allow for an exponent, in general, unless it proves to be unnecessary.

Regression models for passenger vehicle and heavy truck travel have been calibrated to time series data on vehicle travel from 1966-1992 as reported in Highway Statistics table VM-1 and supporting unpublished tables. The results described in Section 8 can be compared to regression models estimated in previous studies by Weinblatt (1989) and Apogee (1990). Previous studies estimated similar equations for four types of larger trucks designated type A-D:

1. Truck A: six-tire trucks;

2. Truck $B$ : single unit trucks with three or more axles;

3. Truck C: three and four-axle combinations; and

4. Truck D: combinations with five or more axles." (Apogee Research, Inc., 1990, p.1)

This classification subdivides each of the two larger truck types reported in FHWA's Highway Statistics, table VM-1 into two parts. Our classification, shown above, uses the same categories for 
single unit trucks as the previous studies. However, we combine all single-trailer units into one class and we define multiple trailer combinations as a separate class. Double-trailer trucks have become a significant component of combination truck traffic following the passage of the Surface Transportation Assistance Act of 1982. That act permitted double-trailer trucks to operate nationwide for the first time over a specified network. As a result, double trailer miles grew explosively from 1983 to 1990 . This transitional period now appears to be over, although with only three years of relatively stable VMT data, one cannot be certain.

It is ORNL's understanding that the FHWA VM-1 series from 1966 to the present uses substantially consistent definitions for vehicle types and a consistent methodology for estimating data. However, in the process of model estimation we have discovered a discontinuity for all types of trucks between the series up through 1985 and those beginning in 1986. This corresponds with a change in data sources from the Highway Statistics Summary to 1985, and individual annual issues of Highway Statistics. The anomalies will be evident in graphical plots shown below.

Vehicle sales $\left(\mathrm{N}_{t}\right)$ were modeled using the same general form of forecasting equation as for VMT. Because of the nature of reasonably available sales and registration data, only three vehicle types are represented:

1. passenger cars and light trucks,

2. other single-unit trucks, and

3. truck tractors.

Vehicle stock dynamics are represented by logistic (s-shaped) scrappage equations. A scrappage equation has been developed for each vehicle type, predicting the number of vehicles scrapped, $\mathbf{s}_{(\mathrm{a}+1)}$ $\mathrm{vt}$, as a function of age, a.

$$
s_{(a+1) v t}=S_{a v(t-1)} \frac{1}{A+e^{b_{o}+b_{1} a}}
$$

In equation $4.3, \mathrm{~S}_{\mathrm{av}(\mathrm{t}-1)}$ is the stock of vehicles of age a in year $\mathrm{t}-1$. The logistic scrappage function contains three parameters. The parameter $\mathrm{A}$ is the inverse of the asymptotic scrappage rate, the scrappage rate that will be approached as the vehicle becomes very old (a becomes large). The term $b_{o}$ determines the scrappage rate of new (zero-year-old) vehicles, while $b$ determines the rate at which scrappage increases with age. Appropriate parameter values for each of the three vehicle types were determined by an iterative process. Initial values were taken from studies by Miaou (1991) and Greene and Liu (1986). The model user may redefine these parameters by specifying 
three values, reasonable ranges for which are given in square brackets: 1) the asymptotic scrappage rate $[0.1-0.25], 2)$ the initial scrappage rate for new vehicles [0.001-0.003], and 3) the number of years it takes to reach half of the asymptotic scrappage rate [8-11].

The resulting scrappage equations were used to construct estimates of total stock for each vehicle type, using estimated historical sales data from the period 1966 to 1992 . As a starting point, a constant level of sales was assumed for the 25 years prior to 1966 , such that when the scrappage equation was applied, the surviving stock exactly equaled FHWA's total stock estimate for 1966. The resulting total stock estimates for each year were compared with FHWA's stock estimates for the three vehicle types, as reported in table VM-1. Parameters of the scrappage equation were then adjusted to achieve a close agreement between the predicted stock and FHWA's historical series.

Surveys consistently show that annual miles per vehicle decline with vehicle age. As a result, new vehicles have a disproportionate impact on fuel use and average fuel economy (Greene and Rathi, 1990). This is reflected in the short-term VMT model in the calculation of fuel economy. ${ }^{4}$ Let $E_{v y}$ be the fuel efficiency of model year (or vintage) y $(y=t-a)$ vehicles in gallons per mile (the inverse of miles per gallon). Let $\mathrm{S}_{\mathrm{avt}}$ be the number of vehicles, and $M_{\mathrm{av}}$ be the average annual miles. We assume that annual vehicle usage declines exponentially with age (a) at a specified rate, $\beta_{v}$, (for passenger vehicles $\beta \approx 5-6 \% / y r$.). Let $M_{v}$ be the miles driven by a new vehicle of type $v$ and $\mathrm{K}_{\mathrm{iv}}$ be a factor representing the relative miles driven by vehicles of type $v$ using fuel type $I$ in comparison with the average for all vehicles of that type. The annual miles of use of an a-year-old vehicle of fuel type $I$ is given by the equation for $M_{\mathrm{ai}}$ below. For the same fuel type, the use of an a-year-old vehicle relative to a new vehicle does not depend on $\mathrm{K}_{\mathrm{iv}}$.

$$
M_{a i v}=\dot{K}_{i v} M_{v} e^{-\beta_{v} a} ; \quad \frac{M_{a i v}}{M_{o i v}}=e^{-\beta_{v} a}
$$

We need these miles per vehicle for the twenty-five vintages in order to estimate fleet average fuel efficiency and fuel type shares. Average fuel efficiency, E, is given by,

\footnotetext{
${ }^{4}$ In principle, it should also be reflected in the estimation of alternative fuel use. However, there is insufficient information on which to accurately estimate annual miles for alternative fuel vehicles. Here we assume that alternative fuel vehicles will be driven the fleet average miles per vehicle, regardless of age. This assumption could easily be changed as more information on alternative fuel vehicles in actual use becomes available, or if FHWA prefers an alternative assumption.
} 


$$
E_{v t}=\left(\sum_{a=0}^{25} M_{a v} S_{a v t}\right)^{-1}\left(\sum_{a=0}^{25} \frac{M_{a v} S_{a v t}}{E_{y} t-a, v}\right)
$$

We define the mileage share of fuel type I as,

$$
\phi f_{i v t}=\frac{\sum_{a=0}^{25} f_{i v y} S_{a v t} \cdot M_{i a v}}{\sum_{j=1}^{7} \sum_{a=0}^{25} f_{j v y} S_{a v t} M_{j a v}} ; y=t-a
$$

The vehicle-type and vintage market shares for each fuel type, $f_{\text {ivy }}$ must be specified by the analyst. Fuel use by fuel type (in gasoline equivalent gallons) can then be estimated using the following equation.

$$
G_{i v t}=f \phi_{i v t} M M_{v t} E_{v t}=f \phi_{i v t} G_{v t}
$$

This equation uses VMT forecasts by vehicle type produced by the econometric model, $M_{v t}$, rather than the miles traveled by vehicle type and age shown in equation (4.5). The roles of equations (4.5) and (4.6) are to estimate the fuel-type VMT shares and vehicle-type efficiencies in an internally consistent manner.

The analyst must specify (or accept default values for) the characteristics of new and pre-existing stock in terms of average fuel economy (MPG), and shares of up to six kinds of fuels (e.g., gasoline, diesel, LPG, CNG, alcohol, and electricity). The short-term stock model predicts the evolution of fleet fuel economy and alternative fuels shares over a ten-year horizon. The model does not predict alternative fuel use in native units, rather it predicts gasoline equivalent gallons of energy use by alternative fuel-capable vehicles. Additional calculations will be required to convert this energy use to alternative fuel use in native units (e.g., kilowatt hours or cubic feet of gas).

Two key simplifying assumptions are made in the above calculations. First, we assume that the existing (base year) stock of vehicles has the same fuel efficiency and fuel-type shares for all vintages. That is, we use the average fuel efficiency and stock fuel type shares for all 25 vintages of the base year. Second, we assume that fuel economy, in terms of energy equivalent units, is the 
same for all fuel types. Evidence to date indicates that for vehicles with similar characteristics, miles per gallon of gasoline equivalent energy differ by only a few percent over the range of nearterm alternative fuels (Greene, 1995). Electric vehicles are a possible exception, but only in terms of energy from the electrical outlet. Taking into consideration electricity generation losses, EVs are roughly equal in energy efficiency to conventional vehicles in terms of primary energy use. 


\section{SHORT-TERM FORECASTING MODEL EQUATIONS}

The short-term forecasting model contains eight econometrically estimated forecasting equations: five vehicle travel forecasting equations and three vehicle sales equations. Vehicle stock size and fuel economy are calculated from these and other projections as described in Section 4 . The general form of the short-term model equations has also been described in Section 4. Model identification and estimation was carried out in two steps. In the first step, an econometric software program (LIMDEP; Greene, 1992) was used to explore alternative model formulations, and determine whether methods other than ordinary least squares (OLS) regression would be required for efficient and unbiased parameter estimation. Because OLS proved to be an acceptable method, the second and final stage of estimation was carried out using a LOTUS 123 spreadsheet containing raw data, all data transformations, and final regressions. The advantage of this approach is that it provides thorough documentation and facilitates annual updating of the regression estimates at the same time. One need only enter the most recent data at the bottom of the input data tables and rerun the spreadsheet regression program to obtain an updated set of parameter estimates. Copies of the spreadsheet are available from the author.

Each of the eight regressions is presented and discussed below. All dependent variables are expressed on a per capita basis (i.e., divided by total U.S. population). Also, all equations were estimated using the logarithms of all variables, indicated by the prefix $\mathrm{Ln}$. Where first differences have been taken the prefix Del is added. Lagged variables are indicated by the suffix [-1]. Key issues discussed for each equation are: 1) any apparent anomalies in the data requiring special handling, 2) which variables appear to be statistically significant, 3) what are the implied sensitivities of VMT and vehicle sales to the exogenous variables and, 4) the degree of fit of model to data. With respect to model fit, one should recall that models estimated in first-difference form generally show much lower $R^{2}$ values than those estimated using simple time-series values. Thus, it is not appropriate to compare $\mathrm{R}^{2}$ values from the difference models estimated here with previous estimates using undifferenced data. 


\subsection{PERSONAL USE VEHICLE VMT EQUATION}

Personal use vehicle VMT includes passenger cars and 2-axle, 4-tire trucks but not motorcycles. Two exogenous variables, personal income per capita $\operatorname{Ln}(\mathrm{PIPC})$ and real gasoline cost per mile $\mathrm{Ln}(\mathrm{RFCM})$, enter this equation. Both variables enter in differenced and undifferenced form. Together with the lagged value of the dependent variable $\operatorname{Ln}(\mathrm{VMTPC}[-1])$, this makes five righthand-side variables altogether. A constant term is also statistically significant. The statistical explanatory power of this equation $\left(R^{2}=0.75\right)$ is respectable. Because the dependent variable is the logarithm of the ratio of current and lagged values of VMT, the standard error of 0.124 , indicates that $95 \%$ of predicted changes in VMT will fall within about \pm 2.5 percentage points of the true percent change in VMT. Observed, Predicted, and Residual values are plotted in Figure 3. As with the truck regressions shown below, the year 1986 shows up as a fairly large residual. Since we know that the data series changes between 1985 and 1986, the statistical significance of the change was tested by inserting a dummy variable for the year 1986. The dummy variable proved to be borderline insignificant, with a t-statistic of -1.69 . In our opinion it would be equally valid to include or exclude the dummy variable. It raises the $R^{2}$ to 0.785 but changes the values of other parameter estimates only slightly. Interestingly, the model appears to fit the most recent data (19871992) best.

Parameter estimates imply short-run income and fuel cost per mile elasticities of 0.62 and -0.04 , respectively. The adjustment parameter, $\rho=0.52$, so that the corresponding long-run elasticities are 1.20 and -0.08 , respectively. The effects of the first differences of these variables is to exaggerate the short-run impact of a fuel cost increase and dampen the short-run impact of income growth. The effects of the differenced variables are transitory, however, disappearing (except for effects via the lagged dependent variable) after one year. The value of the adjustment parameter $(0.52)$ indicates a relatively rapid rate of adjustment. Half occurs in the first year, $75 \%$ by the end of the second, $\mathbf{8 8} \%$ by the third, and so on.

\subsection{2-AXLE, 6-TIRE TRUCKS}

This category includes intermediate-size single unit trucks. Three exogenous variables appear to be significant in this equation: real diesel fuel cost per gallon, $\operatorname{Ln}(\mathrm{RDCG} 2)$, highway miles, Ln(HMILE), and personal income, Del Ln(PNC82). Personal income appears only in differenced form, however, and so its effect is transitory. A dummy variable for the 1985 to 1986 transition is also required and indicates a sudden and permanent $13 \%$ drop in miles for this truck type. Not counting the dummy variable, there are six right-hand-side variables, including the lagged value of 
Figure 3. Personal Use Vehicle Travel Regression Model

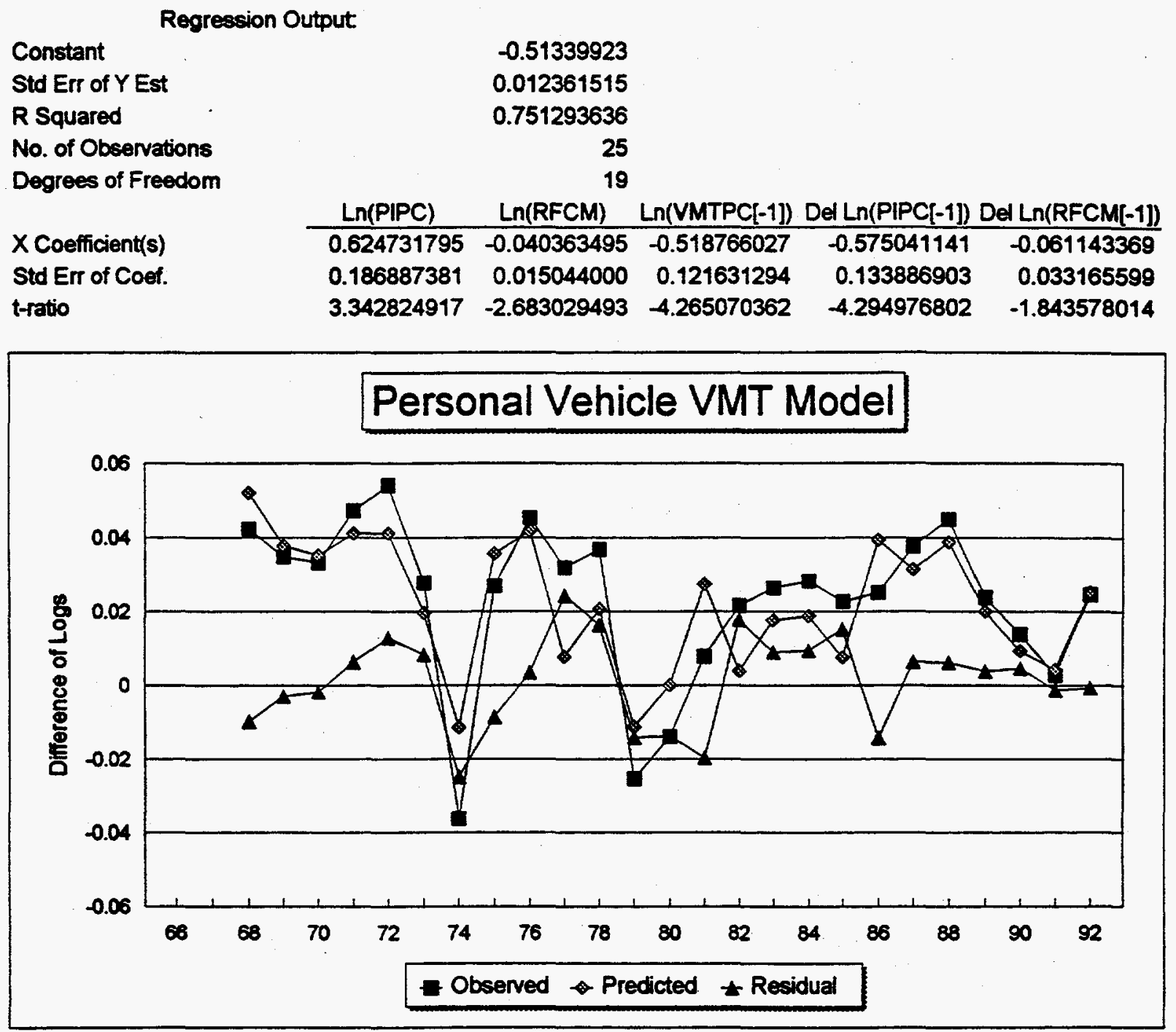


VMT, $\operatorname{Ln}(\mathrm{VMT} 2 \mathrm{~A} 6 \mathrm{~T}[-1])$. The $\mathrm{R}^{2}$ value for this regression is reasonably good, 0.85 , and the residuals show no evidence of trend or heteroscedasticity (Figure 4).

No constant term is included in this equation. Including a constant makes a minuscule change in $\mathrm{R}^{2}$, from 0.8532 to 0.8533 and the $\mathrm{Ln}$ (HMILE) variable becomes insignificant. Apparently either highway miles or a constant term can account for a trend of increasing 2-axle, 6-tire truck vehicle miles. There is little grounds for preferring one formulation over the other. We have chosen to retain the highway miles variable and exclude the constant term because we prefer a plausible known variable to an unknown trend factor. However, we believe that either formulation is acceptable. The coefficient of lagged vehicle miles is -0.20 , suggesting a much slower rate of adjustment than for passenger cars. The implied short- and long-run elasticities for diesel fuel price are -0.024 and -0.12 , respectively. The implied elasticity of VMT with respect to highway miles is .08 in the short-run and 0.4 in the long-run. Changes in diesel fuel price will have a temporarily amplified impact, due to the presence of the differenced value of diesel price. Changes in income and highway miles also show significant transitory effects.

\subsection{OTHER SINGLE UNIT TRUCK VMT}

This class includes all of the heavier single unit trucks, from large vans to cement, garbage, or dump trucks. Only two exogenous variables appear to be significant, real diesel price and gross domestic product $\operatorname{Ln}($ GDP87). The difference of $\operatorname{Ln}(G D P 87)$ is also statistically significant. The model's fit is adequate, $R^{2}=0.77$, but includes the effect of the dummy variable for the 1985 to 1986 data transition, which is highly significant (Figure 5). Interestingly, the coefficient of the dummy variable is positive in this equation and indicates roughly a 30\% jump in VMT in 1986 . The model also requires a constant term.

The adjustment parameter's value is 0.35 , indicating a rate of adjustment intermediate between the personal use vehicle and 2-axle, 4-tire truck VMT equations. The estimated short-run elasticity of diesel fuel cost is -0.126 , with an implied long-run elasticity of -0.355 . Gross domestic product has short- and long-run elasticities of 0.83 and 2.35 , respectively. The long-run elasticity appears to be quite high, especially in view of the moderately high rate of adjustment. These parameters suggest that other single-unit truck VMT will be quite sensitive to economic growth. 
Figure 4. 2-Axle, 6-Tire Single Unit Truck Travel Regression Model
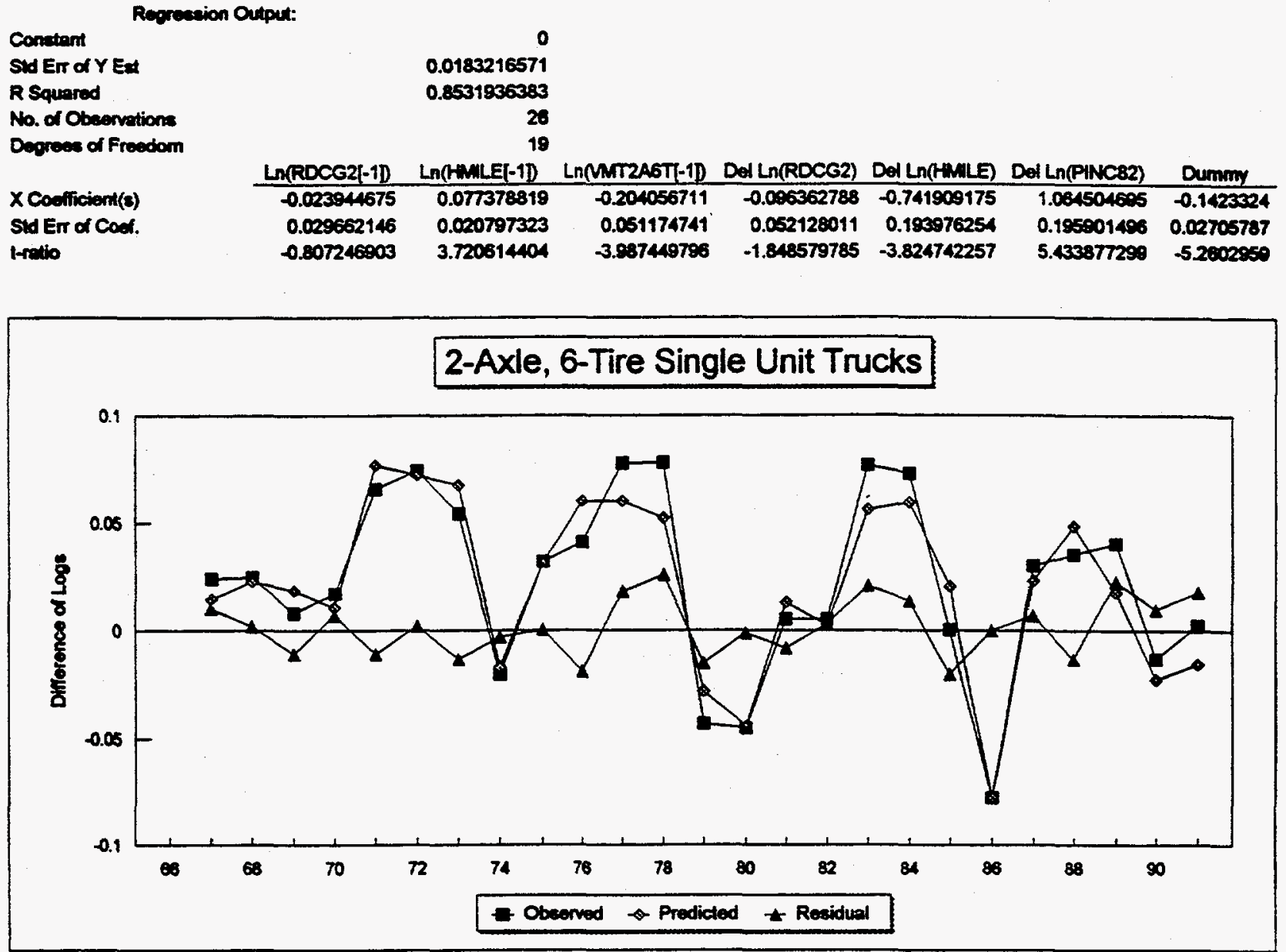
Figure 5. Other Single Unit Truck Travel Regression Model

Regression Output:

Constant

Std Err of Y Est

$R$ Squared

No. of Observations

Degrees of Freedom

$x$ Coefficient(s)

Std Err of Coef.

t-ratio
$-5.5268776$

0.040929264

0.768862703

26

21

\begin{tabular}{rlrc}
$\operatorname{Ln}(R D C G 2[-1])$ & $\operatorname{Ln}(G D P 87)$ & $\operatorname{Ln}(M M T T O T S U[-1])$ & DUMMY2 \\
\hline-0.126262076 & 0.834342914 & -0.354816580 & 0.272627702 \\
0.057403477 & 0.315054985 & 0.118812905 & 0.047547031 \\
-2.199554486 & 2.648245402 & -2.986347141 & 5.733853378
\end{tabular}

\section{Other Single Unit Truck VMT}

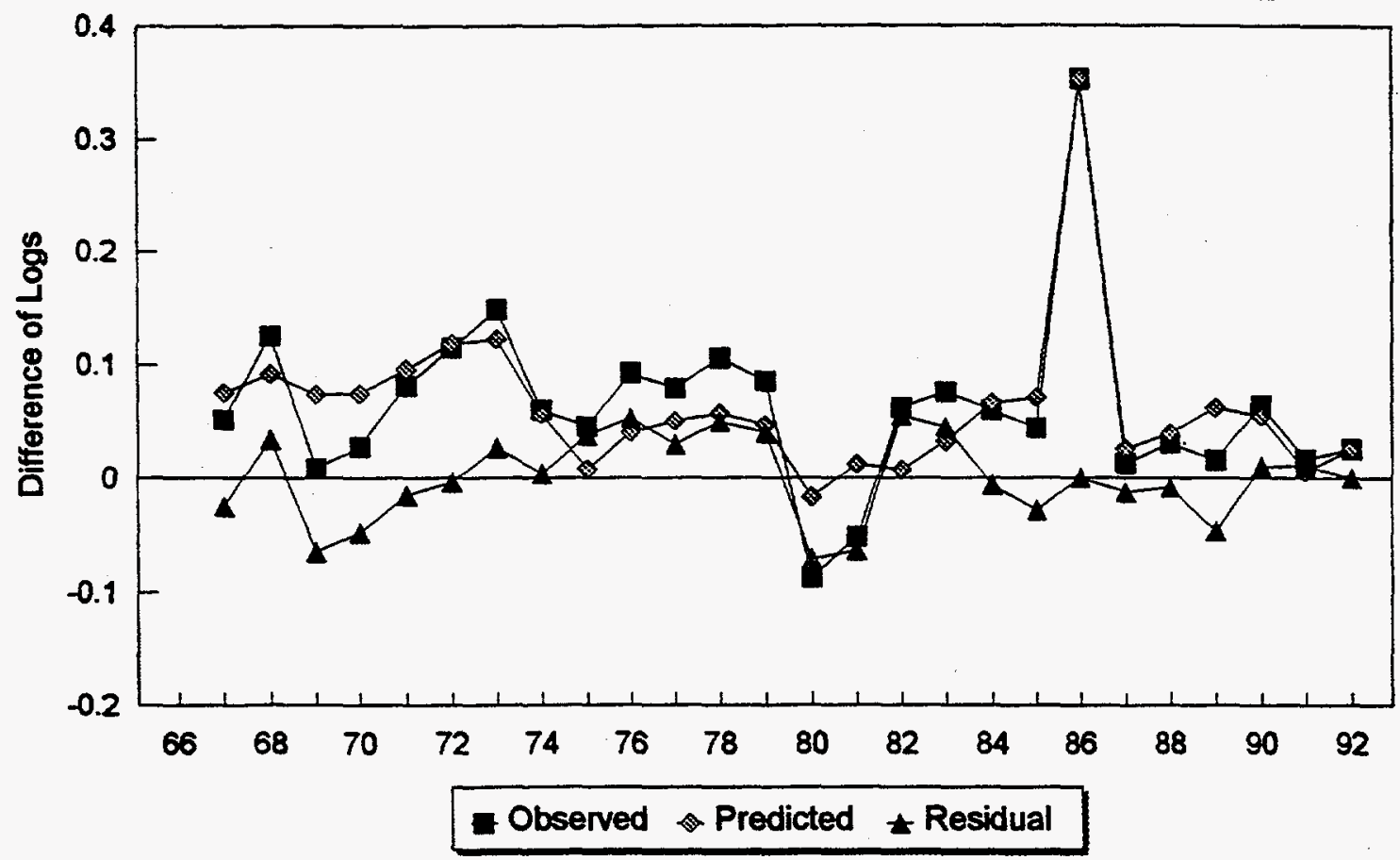




\subsection{SINGLE-TRAILER COMBINATION TRUCK VMT}

This class includes all single-trailer combination trucks, regardless of the number of axles. Exogenous variables appearing in this equation include real diesel cost per gallon, highway miles, and gross domestic product. Gross domestic product appears only in differenced form but twice, as the current and lagged differences. This indicates that heavy truck travel is more sensitive to business cycles than to economic growth, per se. Once again, a dummy variable for the 1985 to 1986 transition appears and is significant. No intercept term is included. Omitting the constant term decreases the $R^{2}$ from 0.8696 to 0.8669 and causes the highway mile variable to become significant. Other parameter estimates are little affected by the change. Once again, it appears that the highway miles variable is capturing a trend that a constant can represent a little bit more accurately. Again, either model will do, but we prefer the one with highway miles. The model's fit is reasonably good, $R^{2}=0.87$, including the effect of the 1986 dummy variable. Plots of the observed, predicted, and residual values indicate that the model follows changes well in direction and magnitude, and that the residuals show no particular problems (Figure 6).

The single-trailer combination truck VMT equation has the slowest estimated rate of adjustment of all, 0.084. This together with the presence of highly significant transitory GDP effects, indicates that VMT will respond very slowly to changes in fuel prices and highway capacity but will swing sharply but temporarily when the economy experiences business cycles. It follows from the slow adjustment rate that short-term and long-term elasticities are very different. The elasticity of fuel price is a mere -0.033 in the short-run but rises to -0.399 over the long-run. The elasticity of highway miles similarly increases from 0.101 for a single year to 1.20 in the long-run. The long-run is a long time, however. It takes more than 10 years for a change in the level of an exogenous variable to achieve $50 \%$ of its long-run effect. Thus, for example, a one-time $10 \%$ increase in highway miles would increase VMT by about $1 \%$ the first year and by 5-6\% after 10 years. Thus, over the forecasting horizon of the short-term model (5-10 years) combination truck VMT will be relatively inelastic with respect to changes in diesel fuel prices and highway infrastructure. It will respond elastically, but temporarily to the rate of economic growth. For example, if the rate of GDP growth were $2 \%$ combination truck VMT would increase by $2.6 \%$. If GDP growth suddenly dropped to $-1 \%$, truck VMT would immediately go down by $1.3 \%$. There would also be a smaller lagged effect of GDP growth.

\subsection{MULTIPLE-TRAILER COMBINATION TRUCK VMT}

This equation which represents all trucks with more than two trailers was the most difficult to estimate. The most important event for double trailer trucks during the 1966-1992 period was the 
Figure 6. Single Trailer Combination Truck Travel Regression Model

Conctant

Std ErT of $Y$ Eat

$R$ Squared

No. of Observations

Deprees of Freedom

$X$ Coefficient(e)

Std Ert of Coef.

tretio
Regreasion Output:

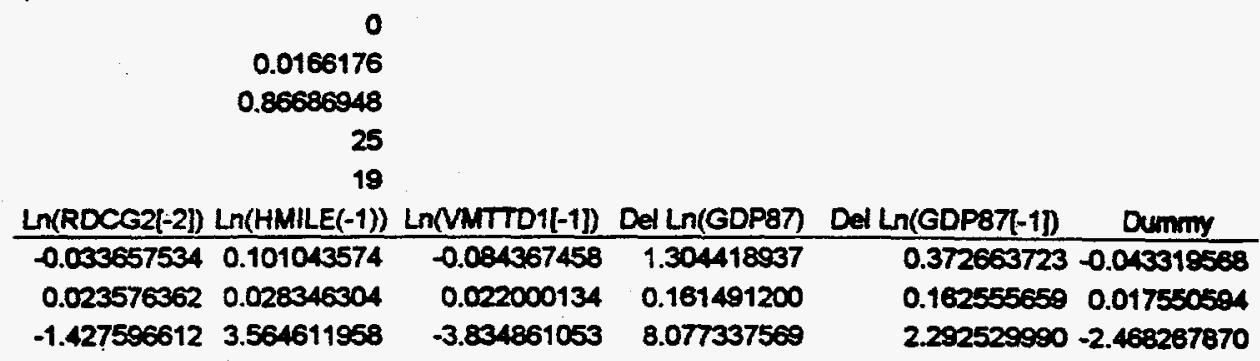

\section{Combination Truck Miles}

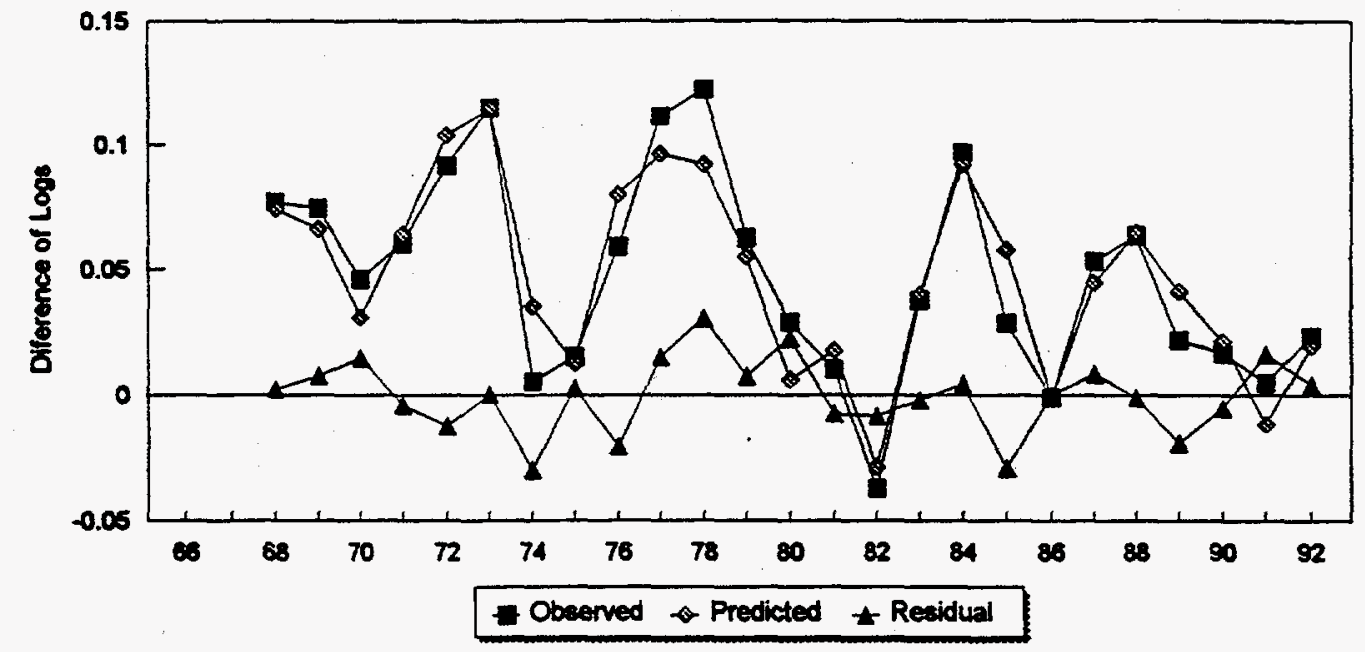


passage of the Surface Transportation Assistance Act of 1982 which for the first time permitted doubles to travel nationwide over a specified network. This initiated a sudden and striking growth of double trailer traffic which appears to have continued until 1990. In addition, due to the relatively small numbers of multiple trailer trucks prior to 1982 , the accuracy of the multi-trailer VMT estimates is probably much lower than that for other truck types. We could find no way to include the 1983-1989 data and still estimate a meaningful VMT forecasting equation. These years were omitted. In addition, the years from 1976-1978 appeared to be outliers (abnormally high) and so a single dummy variable was added to account for them. Two exogenous variables were significantly related to the remaining data: lagged gross national product, $\operatorname{Ln}($ GNP82[-1]) and lagged real diesel fuel price, $\operatorname{Ln}(\mathrm{RDCG} 1[-1])$. Given all of the above, the $\mathrm{R}^{2}$ of 0.75 seems reasonable (Figure 7).

In the short-run, multi-trailer VMT appears to be inelastic with respect to economic growth. Over the long-run, sensitivity to GNP grows enormously. The short-run GNP elasticity of 0.70 becomes 4.6 in the long-run. Fortunately for forecasting purposes, the adjustment rate is very slow, so that over a period of ten years only about half of the long-run effect will be realized. How fast multitrailer VMT will increase for a given rate of economic growth, however, is also a function of the equation's constant term. As we pointed out above, this constant term can reflect a trend as well as an adjustment for the units in which the exogenous variables are expressed. Estimation of a better equation must probably await additional years of data.

\subsection{PERSONAL USE VEHICLE SALES}

In general, better fits were achieved for the vehicle sales models as evidenced by $R^{2}$ values ranging from 0.89 to 0.92 . The personal use vehicle equation, which covers passenger cars and light trucks, achieved an $R^{2}$ of 0.92 . Two exogenous variables are significant in addition to the lagged dependent variable: gross domestic product and the prime interest rate. GDP, however, enters in three forms: 1) the lagged value of GDP, 2) the difference of current GDP, and 3) the difference of lagged GDP. In fact, it is a property of the error corrections model that when both the current and lagged differences are present, including either the current value of GDP or its lagged value will give identical results in terms of both coefficient estimates and fit. The prime rate enters only in first difference form. In general, measures of vehicle price or cost were not statistically significant. No intercept term is included. The model captures well the swings in sales associated with business cycles. Peaks in 1971, 1976, and 1983-84 are hit almost exactly (Figure 8). Likewise troughs in 1970,1974 and 1980 are fit well. Since vehicle sales are measured relatively accurately, it is possible that the greater accuracy of the sales data is responsible for the superior fit of the model. 
Figure 7. Multiple Trailer Combination Truck Travel Regression Model

Constant

Regression Output:

Std Err of Y Est

$R$ Squared

No. of Observations

Degrees of Freedom

$X$ Coefficient(s)

Std Err of Coef.

t-ratio
$-3.1823782198046$

0.06300063632052

0.7515073688878

18

13

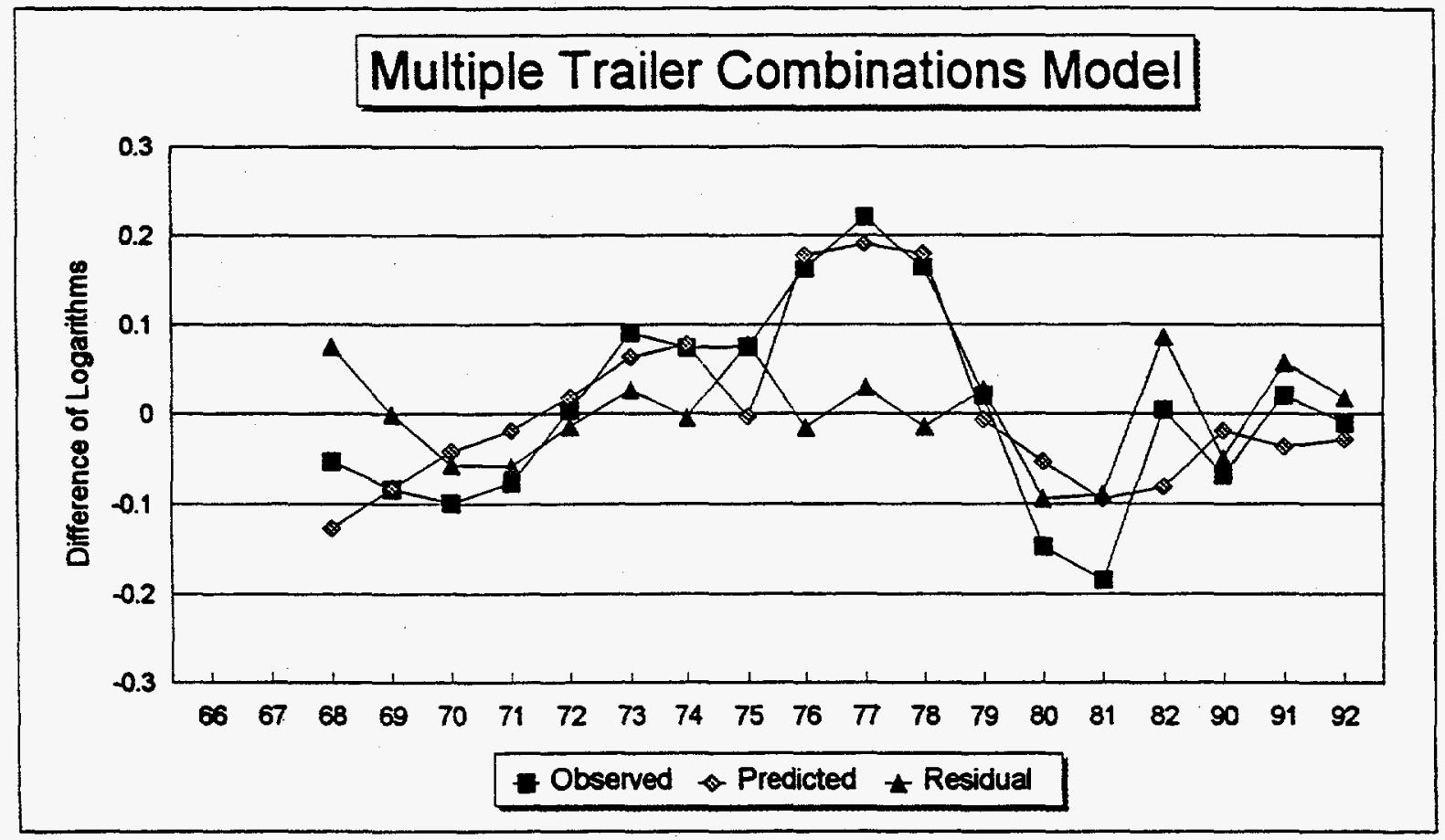


Figure 8. Personal Use Vehicle Sales Regression Model

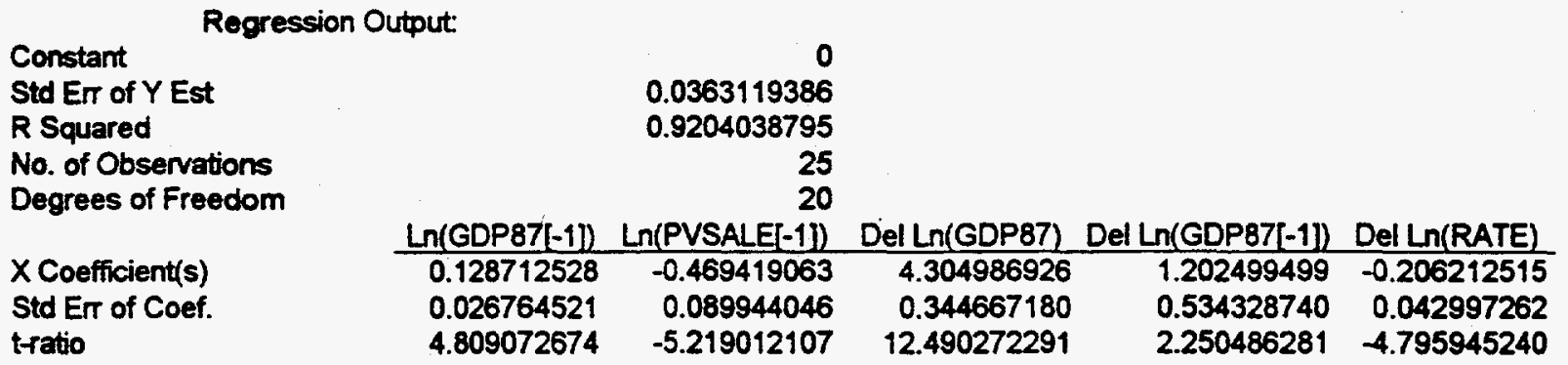

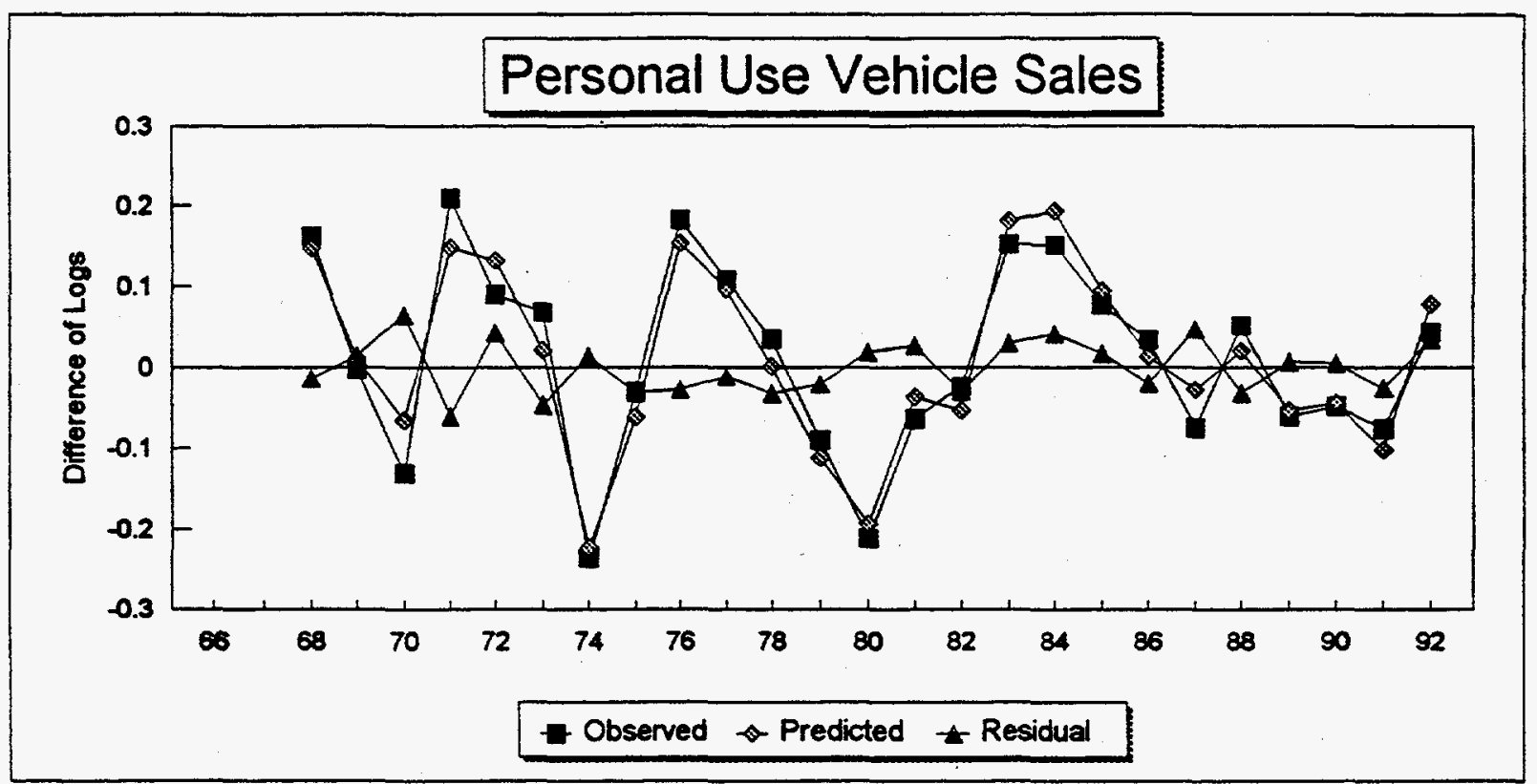


The estimated adjustment rate parameter of 0.47 indicates a relatively rapid adjustment to changing economic conditions. The short-run GDP elasticity is 0.13 and the long-run is 0.27 , indicating that vehicle sales are inelastic with respect to GDP. On the other hand, vehicle sales are very sensitive to short-term economic fluctuations but these responses are transitory. The prime interest rate is the only measure of vehicle cost in the forecasting equation. Its effect is negative, as expected, and transitory. The upshot is that personal vehicle sales will respond primarily to economic growth, but they will grow more slowly than the economy. If forecasts do not contain business cycles, the increase in sales will be gradual and smooth. If business cycles are present, sales trends will amplify the fluctuations.

\subsection{SINGLE UNIT TRUCK SALES}

Available sales data do not distinguish among different types of heavier (than $10,000 \mathrm{lb}$. GVW) single unit trucks. The single unit truck data series used here was obtained by subtracting light truck and tractor sales from total truck sales. Although this is probably the best method available short of purchasing a data series from a commercial vendor, it has an undesirable property. Because single unit truck sales are small relative to total truck sales, errors in light trucks sales or total truck sales statistics will be amplified relative to single unit sales. The other key feature of the single unit truck sales data is an apparent trend of declining sales over time. We hypothesize that this trend has to do with the relative boom in light truck sales over the same period. More specifically, we suspect that light trucks were being substituted for larger single unit trucks at the same time that they were being substituted for passenger cars. This hypothetical trend was represented as follow. During the decade of the 1970s, light trucks increased their market share of all new vehicle sales by approximately ten percentage points (roughly from $15 \%$ to $25 \%$ ). Over this period, annual lightduty vehicle sales ranged from about 10 million to over 15 million units. Based on this, we created a smooth trend increasing from 50,000 units in 1966 to one million by 1980 , and trending toward about 1.2 million eventually. More precisely, a logistic curve of the following form was used.

$$
\operatorname{TREND}(t)=\frac{1190000}{1+e^{28.9-0.36}}
$$

This variable turns out to be statistically significant with the expected negative sign; the greater the trend to light trucks the lower the sales of other single unit trucks. GDP also enters as the lagged value of GDP and differences of current and lagged values. Values of sales for 1971 to 1992 were used to estimate the forecasting equation. Data for 1968-70 were considered to be outliers. Given all of this, the fit of model to data $\left(R^{2}=0.89\right)$ is reasonable (Figure 9). 
Figure 9. Single Unit Truck Sales Regression Model

Constant

Std Ert of $Y$ Est

$R$ Squared

No. of Observations

Degrees of Freedom

$X$ Coefficient(s)

Std Err of Coef

tratio

\section{Regression Output:}

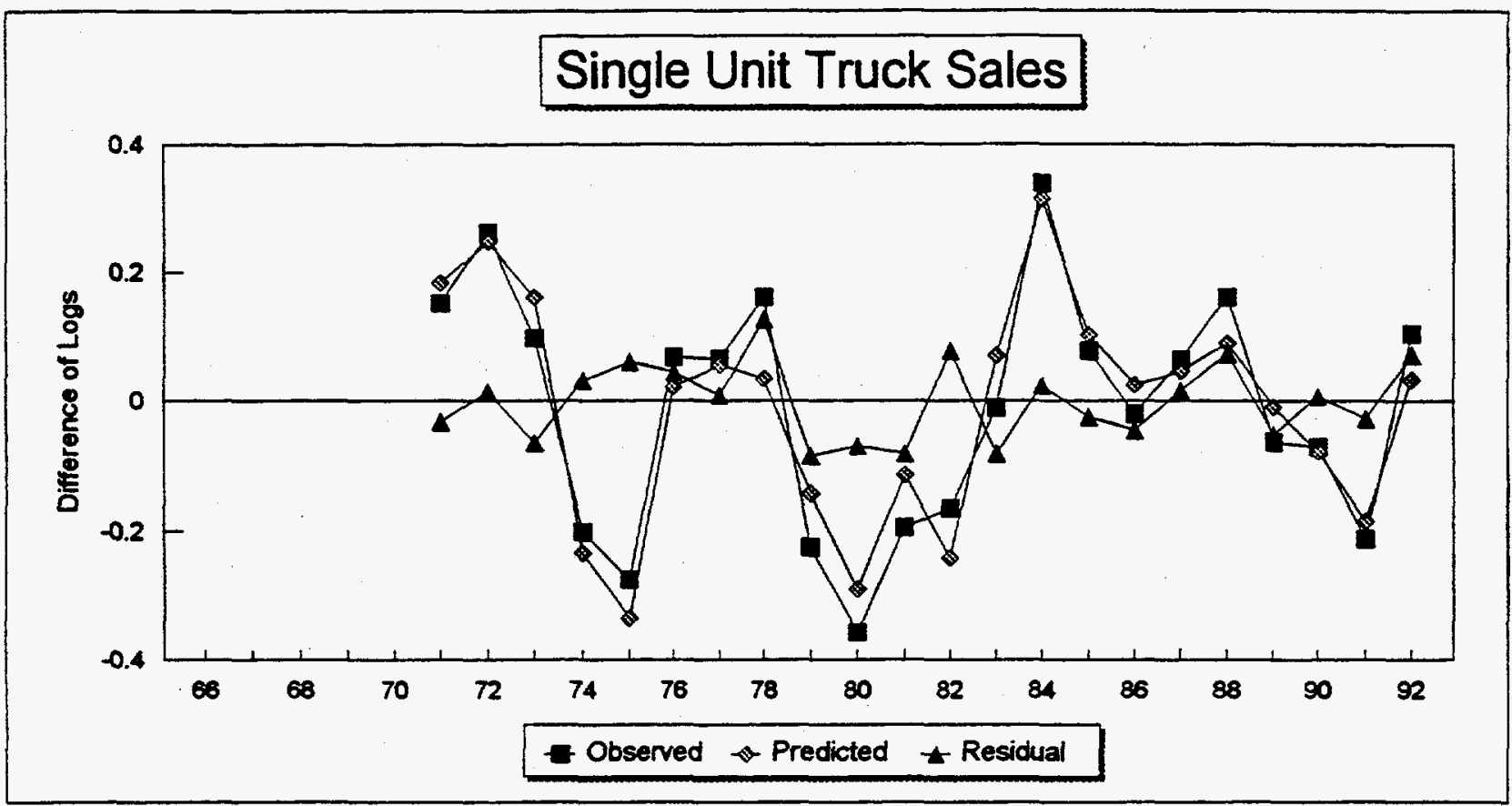

0.069012145

0.892395445

22

16

In(GDP87[-1]) Ln(TREND[-1]) $0.433913702-0.247041230$

$0.177760209 \quad 0.056715162$

$2.441005802-4.355823416$ 0.073675885

Del Ln(GDP87) Del Ln(GDP87(-1)) 5.742980494 0.756790037 1.714521858 0.783448180

2.188430456
3.415278363 $-0.313853029$

\section{Single Unit Truck Sales}


The implied adjustment rate for single unit truck sales $(0.31)$ is slower than that for personal use vehicles. The short-run response to GDP is 0.43 , but because of the implied adjustment factor longrun sales are GDP elastic (1.38). Once again, sales respond very strongly to short-term swings in GDP, but the responses are transitory.

\subsection{TRUCK TRACTOR SALES}

Because a truck tractor may typically be used to pull one, two, or three trailers, it makes no sense to attempt to predict tractor sales by number of trailers pulled. Truck tractor sales are also not available except by special purchase from a commercial vendor. The data series used here was estimated by multiplying the total sales in each truck weight class by the fraction of vehicles in that weight class that were tractor trailers, according to the 1987 Truck Inventory and Use Survey (TIUS). Despite this, the model $\mathrm{R}^{2}$ is good, 0.92 (Figure 10). GDP enters this equation in lagged and differenced form, as do the lagged value of the prime rate and the differenced, lagged value of combination truck VMT.

Adjustment is relatively rapid in this model (0.69), resulting in long-run and short-run elasticities that are close in value. The short-run elasticity of GDP is 0.51 , the long-run value is 0.74 . Similarly the long- and short-run elasticities with respect to the prime rate are -0.12 and -0.18 . A change in the rate of increase in GDP will cause a transitory change in tractor sales, as will a change in the rate of increase of tractor vehicle miles. As Figure 10 shows, this model tracks fluctuations in truck tractor sales quite well. 
Figure 10. Truck Tractor Sales Regression Model

Constant
Sid Err of Y Est
$R$ Squared
No. of Observations
Degrees of Freedom
X Coefficient(s)
Std Err of Coef.
t-ratio

\section{Output:}
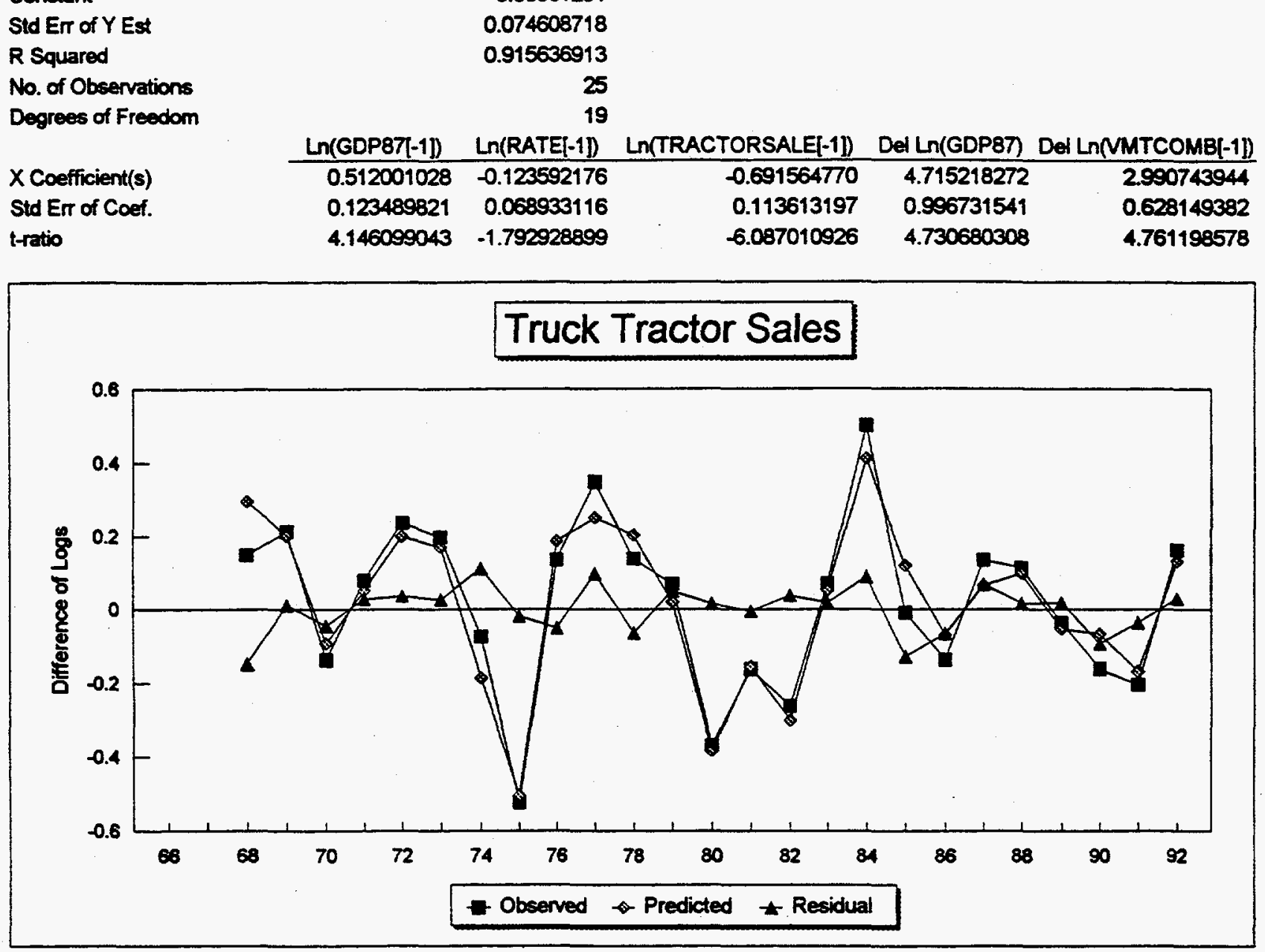



\section{LONG-TERM VMT FORECASTING MODULE}

In contrast to the statistically based short-term forecasting module, the long-term forecasting module uses structured, parametric methods for predicting passenger and freight activity. The Passenger VMT Model forecasts light duty vehicle travel using a hybrid of demographic-based parametric (or cross classification) and economic (constant elasticity) methods. This allows some sensitivity to fuel costs and economic growth to be introduced into a primarily demographically driven forecast of passenger travel. The Freight Vehicle model is driven by economic output (GNP) which is used to forecast intercity and local ton-miles. Intercity ton-miles are shared to trucks versus other modes and then among heavy truck types by the VMT Shares Module, as a function of base-year shares and changes in generalized cost per ton-mile. Ton-miles are translated into vehicle-miles by means of load factors based on TIUS data--but load factors are changeable by the user. Policy sensitive generalized cost-per-ton-mile measures for rail and truck type are computed in the Truck Cost/Policy Module. A VMT Shift Model uses multinomial logit equations to share out VMT by functional highway class and vehicle type, based on past shares and changes in relevant variables.

\subsection{PASSENGER VEHICLE TRAVEL MODEL DESIGN}

In 1991, passenger cars and light trucks accounted for $96 \%$ of all highway vehicle-miles. ${ }^{5}$ In this model, we propose to combine passenger car and light truck miles for the purpose of developing an aggregate vehicle miles forecast. ${ }^{6}$ The reason for combining light duty vehicle VMT for forecasting purposes is that, for the most part, passenger cars and light trucks perform a similar function: passenger transport. The Residential Transportation Energy Consumption Survey (U.S. DOE/EIA, 1990, table 6) estimates that households' vehicle stocks in 1988 consisted of 110 million passenger cars and approximately 38 million light trucks (including pick-ups, vans, and recreational vehicles). This comprised $90 \%$ of the passenger cars and $80 \%$ of light trucks on the road in 1988 (Davis and

${ }^{5}$ Motorcycles are not included in this calculation. Light trucks are 2-axle, 4-tire trucks, as defined in Highway Statistics 1991 (FHWA 1991).

${ }^{6}$ We concur with Weinblatt's (1989) reasoning in combining passenger car and light truck VMT. Both vehicle types serve predominantly the same function, personal transportation. Variations in the market shares of the two vehicle types are due to factors (such as design decisions and shifts in consumer tastes) that have yet to be adequately captured in detailed disaggregate choice models and are not likely to be well modeled by an aggregate VMT model. 
$\mathrm{Hu}, 1991$, table 3.2). Furthermore, data on light truck use from the TIUS (Davis and Hu, 1991, p. A-12) indicates that $69 \%$ of all 2-axle, 4-tire trucks and $63 \%$ of their miles traveled are predominately for personal (not business) use and passenger transport. Thus, business use predominately for passenger transport is excluded; adding it would further increase the use of trucks as passenger vehicles.

In brief, light duty vehicles dominate total vehicle-miles. Light duty vehicles are predominately household vehicles and are predominately used for passenger transport, regardless of their designation as light trucks or passenger cars. Because of this, and because of the near impossibility of breaking down vehicle-miles and vehicles by purpose of use, we combine passenger cars and light trucks for the purpose of forecasting vehicle travel.

Personal travel by motor vehicle is determined by an exceedingly complex interaction of social and personal values; the spatial arrangement of residences, workplaces, and other activities; the requirements and options for earning a living and raising a family; the technology and economics of motor vehicle travel; and the availability and characteristics of alternatives. Despite the obvious complexity of the determinants of vehicle travel, aggregate vehicle travel can be adequately modeled, from a statistical point of view, with only three or four independent variables: number of drivers, income or GNP, stock of motor vehicles, and vehicle cost per mile (Greene, 1992; Gately, 1990; Weinblatt, 1989; Sierra Research, 1990; Southworth, 1986). Thus, while the details of individual travel decisions and the determinants of long-term trends are complex, the resulting time trend of travel can be statistically explained by only a few key aggregate indicators.

The chief limitation of statistical or econometric approaches to VMT forecasting is their tendency to extrapolate historical trends indefinitely. The historical data cover a period of rapid expansion in the numbers of licensed drivers, vehicle ownership, and highway infrastructure. It has been argued that today all of these factors are approaching "saturation" levels (Kitamura, 1988; Lave, 1992). Although a strict interpretation of the concept of saturation to vehicle ownership and travel demand is incorrect, there are definitely levels beyond which we may expect the influence of determining factors on travel demand to decrease substantially. ${ }^{7}$ For example, when vehicle ownership levels are low, increases in the stock of motor vehicles materially increases their availability to travelers and will have a substantial effect on travel demand. Now that vehicle stock levels exceed one per licensed driver, the effect of further increases in vehicle ownership rates are likely to have a much smaller, and perhaps negligible, effect on travel demand. Indeed, Greene (1992) found no statistically significant relationship between vehicle stock and VMT, given that income and the number of drivers were accounted for. Although estimating parameter trends by

\footnotetext{
${ }^{7}$ For a good discussion of saturation effects, see Pisarski (1992), Chapters 1 and 2.
} 
means of econometric approaches is theoretically possible, in practice it may not be feasible, due to the correlations among explanatory variables and the small amount of variability unexplained by even simple VMT models.

An alternative is to use parametric approaches for forecasting the effects of variables whose relationship to VMT is expected to change in the future (Maring, 1974; Greene, 1986) but still make the forecast sensitive to income and travel costs. Parametric travel forecasting approaches are, in principle, similar to constant travel time budget methods (Kirby, 1981; Golob, Beckmann, and Zahavi, 1981) which assume that households have a fixed budget for travel time, travel cost, or generalized travel cost. The virtue of constant travel time budget methods is that they recognize that travel is highly constrained by the availability of time for travel. This would seem most likely to be true for high income, highly motorized societies such as the U.S.; however, empirical research has indicated a tendency for the average amount of time spent traveling to be relatively constant across wide variations in geography, culture, and technology (Tanner, 1981). This relative constancy suggested that models could be developed which depend on the speed of travel and a few other demographic variables. Traditional econometric forecasting approaches do not recognize the time constraint, although Golob, Beckmann, and Zahavi (1981) have developed the relevant economic theory. Without a constraint on travelers' time, econometric models tend to produce unrealistic long-range forecasts in which continued income growth drives levels of vehicle travel per capita to unprecedented and sometimes absurd levels.

Parametric forecasting methods have been chiefly motivated by a desire to reduce the number and complexity of independent variables required by forecasting models, to rely on independent variables that can themselves be forecasted with a high degree of accuracy, and to restrain the growth of vehicle travel per traveler. Perhaps the most predictable factor which strongly influences travel is the demographic structure of the population. Both the age distribution and gender of the driving-age population can be predicted for 20-30 years into the future since most of these individuals have already been born. Maring (1974) proposed estimating total VMT by the following simple formula:

$$
V M T=\sum_{i} P_{i} \times\left(\frac{D}{P}\right)_{i} \times\left(\frac{V M T}{D}\right)_{i}
$$

where

$$
\begin{aligned}
& P=\text { population, } \\
& D=\text { number of licensed drivers, and }
\end{aligned}
$$


$I=$ age group index.

Maring's approach has three important strengths:

1) it rests on the population age structure which can be predicted with relative accuracy;

2) it makes use of license-holding rates which do have and have been approaching a clear saturation point of $100 \%$; and

3) it allows one to construct scenarios by varying the number of miles per licensed driver.

Greene (1987) added a further breakdown of the population by gender, noting important trends in license-holding rates for females in the U.S. and a nearly 2-to-1 ratio of miles driven by male versus female drivers across all age groups. Greene (1987) concluded that of all the factors he considered, increased vehicle-miles by female drivers could have the greatest impact on future travel growth. The cross classification by age and gender was also used by FHWA in developing forecasts for the Future National Highway Program (FHWA, 1987). The additional breakdown by gender will not necessarily add to the accuracy of VMT forecasts, but it will allow the forecaster to anticipate a potentially significant trend of driving by women. ${ }^{8}$

Historical data show that miles per driver ([VMT/D $]_{\mathrm{ij}}$, where $I=$ age group index, and $j=$ gender) have been consistently increasing over time for all age groups for both genders. A number of factors appear to be responsible. Pisarsky (1992, Chapters 1 and 2) cites decreased average load factors (persons per car), increased trip lengths, and increased rates of trip-making as the proximate causes, and decreased household size, increased license-holding, greater vehicle availability, and changes in metropolitan structure and residential and workplace location as the underlying determinants.

The fact that miles per driver and license-holding rates have changed significantly over the past thirty years demands that a comprehensive model of vehicle travel must allow for trends and changes in these variables. Since license-holding rates for both men and women are nearing saturation levels, we will focus on miles per licensed driver (in aggregate, rather than by age and gender). The current version of the aggregate VMT model represents miles per driver as a function of vehicle cost per mile (including fuel price and fuel economy), income, and the average speed of travel. It should be possible to extend this model to include average population density as a measure of changing spatial structure, and the supply of highway miles. Rathi et al. (1991) showed that in urban areas of over million population and less than 2 lane-miles of primary highways per 1,000 persons, travel demand appeared to be constrained by lack of supply. This suggests that an

\footnotetext{
${ }^{8}$ Indeed, there is evidence in the 1990 Nationwide Personal Transportation Survey that this trend has already begun (Pisarsky 1992, Chapter 5).
} 
appropriate measure of supply could be developed that would allow for the estimation of the effect of congestion on travel demand. Given estimates of highway lane-miles, volume-per-capacity measures could be calculated from these projections. If historical relationships between volumecapacity ratios and vehicle travel can be estimated, this could allow for prediction of the effects of highway supply on travel speeds and congestion. If travel time budgets are approximately constant, the elasticity of travel per driver with respect to average speed should be about 1 .

In principle, model parameters may vary for each demographic group. Unfortunately, readily available data do not allow statistical estimation of group-specific cost per mile and VMT. Aggregate cost and income elasticities have been estimated by several studies (e.g., Greene, 1992; Gately, 1990; Weinblatt, 1989). These have been used in selecting initial model parameters.

The full long-run passenger VMT forecasting equation is,

$$
\begin{aligned}
& V M T_{t}=\left(\frac{Y_{t}}{Y_{0}}\right)^{\alpha}\left(\frac{k_{t}}{k_{0}}+\frac{\left(\frac{p_{t}}{M P G_{t}}\right)}{\left(\frac{p_{0}}{M P G_{0}}\right)}\right)^{\beta}\left(\frac{\frac{(\$ / h r)_{t}}{v_{t}}}{\frac{(\$ / h r)_{0}}{v_{0}}}\right)^{\gamma} \times \\
& \times \sum_{j=1}^{n} \sum_{i=1}^{m} P_{i j t}\left(\frac{V M T}{P M T}\right)_{i j t}\left(\frac{P M T}{P}\right)
\end{aligned}
$$

where,

$\alpha=$ the income elasticity of highway passenger travel (1.25 to 2.0$)$,

$Y=$ personal income per capita,

$\beta=$ the elasticity of vehicle travel with respect to cost per mile $(-0.3$ to -1.0$)$,

$k=\mathrm{a}$ constant representing nonfuel variable costs per vehicle mile,

$p=$ the price of motor fuel (assumed to be gasoline),

$M P G=$ average fuel economy of passenger vehicles in miles per gallon, and

$\gamma=$ elasticity of travel with respect to the time cost of travel $(-1.0)$,

$(\$ / h r)=$ the value of time spent in highway travel $(\$ 8-\$ 10)$,

$v=$ the average speed of highway passenger travel (30)

$P M T, V M T, P=$ passenger and vehicle miles of travel and population, respectively,

$i, j, t=$ index age group, sex, and year, respectively. 
Reasonable ranges for the values of key parameters are shown in parentheses.

Since Maring (1974) proposed forecasting vehicle travel based on miles per licensed driver and the rate of drivers' licenses per capita by age category, drivers' licenses have becomes almost universal. Today essentially all those entitled to hold a drivers' license have one, regardless of age or sex (Figure 11). The only exceptions may be the very youngest and very oldest age groups. As a result, this factor is now of little use for predicting changes that may affect future vehicle travel.

FIGURE 11. LICENSED DRIVERS, 1992 DISTRIBUTION BY SEX AND AGE

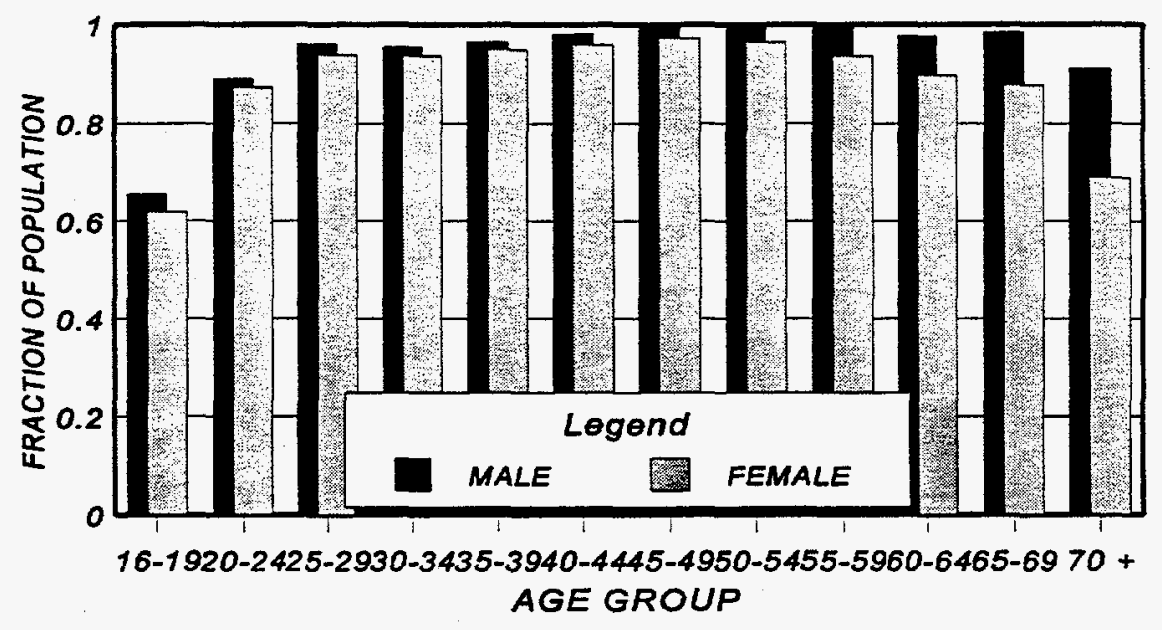

Recent 1990 and 1983 Nationwide Personal Transportation Surveys (Hu and Young, 1993) show significant increases in passenger travel and even greater increases in vehicle travel, as a result of declining vehicle occupancy rates. Statistics published by the FHWA (1991) indicate that occupants per passenger vehicle decreased from 1.69 in 1983 to 1.58 in 1990. This alone is enough to produce a $1 \% / y e a r$ rate of growth in vehicle travel. Further decreases in vehicle occupancy rates are possible and could contribute substantially to future growth in vehicle travel. To permit representation of trends in occupancy, we have restructured equation (6.2) by decomposing vehicle miles per capita into two parts: 1) highway person-miles per capita, and 2) the ratio of miles driven to person-miles traveled, which we call the driving rate. Like license-holding rates, driving rates are theoretically bounded by zero and one, at least for the present. Also like license-holding rates, driving rates are approaching saturation for certain age-sex categories, particularly males aged 30-65 (Figure 12). However, driving rates remain in the vicinity of $40-70 \%$ for females, constituting a substantial opportunity for additional future declines in occupancy rates and increases in vehicle travel. By 
including the driving rate as an explicit factor in the model, we make it possible to forecast vehicle occupancy rates. Put another way, vehicle occupancy becomes an endogenous variable.

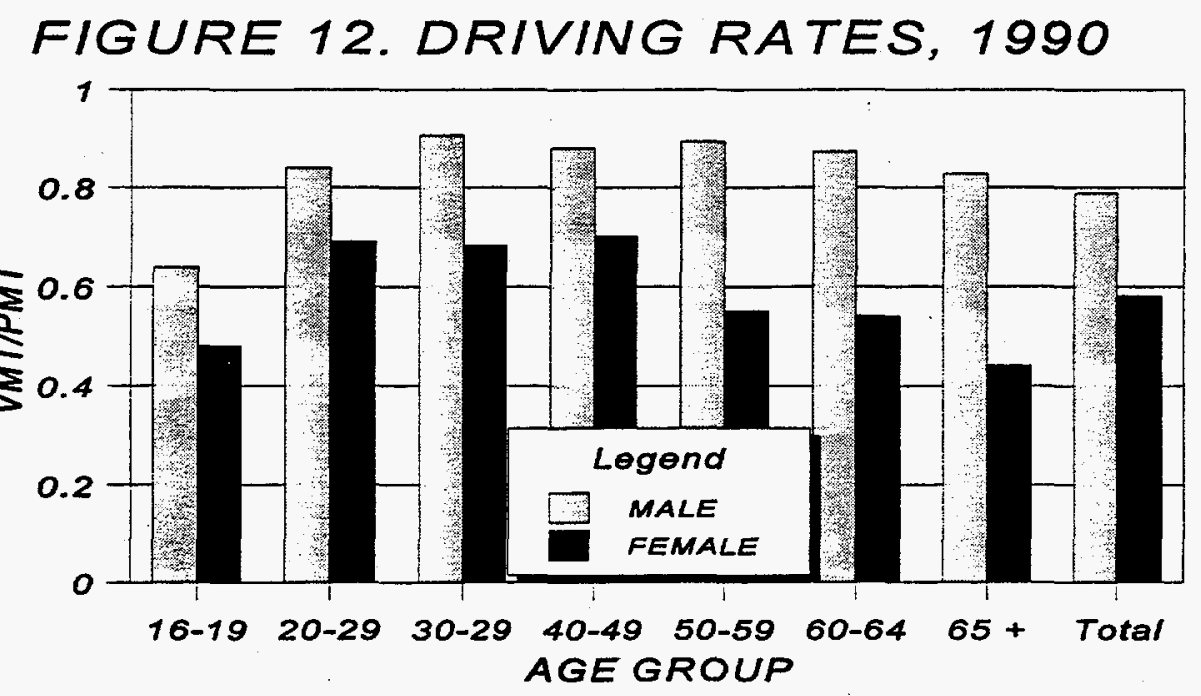

By setting the value of highway person-miles of travel per capita in equation (6.2) to its value at $t=0$, we thereby define the elasticities with respect to income $(\alpha)$, monetary cost per mile $(\beta)$, and time cost per mile $(\gamma)$ as elasticities of highway person-miles per capita. Equation (6.2) thus contains three principle factors: 1) economic factors affecting the demand for personal travel, 2) demographic factors, and 3) vehicle occupancy factors. The inclusion of the time cost of travel allows for a future enhancement of the model to permit highway infrastructure investments to influence the speed of travel via the relationship of vehicle miles of travel to the supply of highway lane miles, and by relating this aggregate volume/capacity ratio to the average speed of highway travel.

In principle, this model could be statistically estimated using historical vehicle travel data. However, for long-run forecasting, it is more important that the parameters used are plausible, consistent with theory, and reasonably consistent with the existing literature on vehicle travel demand. Thus, it is not necessary that the parameters be statistically estimated. A hybrid parametric-econometric method similar to this has been used in calibrating the Energy Information Administration's new NEMS transportation sector forecasting model. ${ }^{9}$

${ }^{9}$ According to a personal communication with Mr. John R. Meyer, Energy Information Administration, U.S. Department of Energy, Washington, DC. 


\subsection{FREIGHT VEHICLE TRAVEL MODEL DESIGN}

While growth in passenger travel is driven primarily by demographic factors, freight demand is primarily driven by the level of economic activity (FHWA, 1987b, p. 13), influenced by the composition of economic output, and the geography of production and consumption. The economy generates demand for the movement of both intermediate goods as inputs to production and for the distribution of final products to consumers. The composition of goods to be moved (in terms of their density and shipment size), the logistic requirements associated with their use (e.g., time sensitivity of delivery), the spatial distribution of production and consumption sites, and the availability and characteristics of competing transport modes are the key determinants of highway freight demand. Most of these factors are best represented by a model that explicitly portrays the generation of freight at origins, demand at destinations, and choice of mode and route of shipment over explicit transportation networks (Friesz and Tobin, 1983).

Only a few aggregate (aspatial) freight demand models have been developed. In these models, two principal methodologies have been employed: 1) econometric estimation of vehicle use and stock equations (Apogee, 1990; Weinblatt, 1989; Greene, 1984), and 2) sectoral-output-driven empirical models (Mintz and Vyas, 1991). The chief disadvantage of econometric models is that unless some way is found for coefficients to change over time, they will extrapolate trends from a period of rapid expansion of heavy truck travel. Apogee (1990) and Weinblatt (1989), for example, estimated (constant) GNP elasticities of truck-miles on the order of 1 to 1.7, with the higher elasticities associated with the larger trucks. FHWA (1987b, p. 41) used a simple linear model with an elasticity of 1.5 for 1985 . This pattern reflects a historical trend toward larger trucks. As FHWA (1988) observed,

The relative shift in VMT towards truck configurations with more axles reflects a steady increase in maximum allowable vehicle sizes and weights. (p. 18)

This trend may or may not continue, and, in any case, one would prefer that the policy changes behind the trends be explicitly modeled.

Alternatively, one may forecast ton-miles as a function of economic output, as is done in the Transportation Energy and Emissions Modeling System (TEEMS) model (Mintz and Vyas, 1991, Ch. 3). The TEEMS model contains a macroeconomic model of the U.S. economy that forecasts commodity-sector growth rates. Growth in output by sector is converted to ton-miles by expanding base-year ton-miles by commodity type and mode. Truck ton-miles are then converted to vehiclemiles by using commodity-specific load factors (excluding truck type). That is, a ton-mile of commodity $I$ is converted to a certain number of generic heavy truck miles. Next, vehicle-miles for 
each commodity type are shared to four gross vehicle weight (GVW) classes using commodityspecific allocation factors derived from TIUS data.

The long-term truck freight model is based on projecting ton-miles by three distance categories (local, short haul up to 150 miles, and intercity) as a function of aggregate GNP. The three distance categories are defined by the nature of available data, but also reflect the different functions of intercity commodity transport versus local distribution. ${ }^{10}$ Ton-miles are distributed by mode and truck types by means of a model directly linked to truck size and weight policies (Figure 13). First, economic output is used in separate equations to predict intercity and local ton-miles transported." Suitable annual data are available in Smith and Wilson (1993) for intercity shipments. Local, shorthaul, and intercity ton-miles may also be estimated based on the TIUS (FHWA/U.S. DOT, 1987b). Short-haul ton-miles are treated as a mixture of local and intercity ton-miles, and the distribution of traffic by truck type is estimated as a weighted average of the local and intercity distributions.

A relationship between local ton-miles and economic output can be estimated via an analysis of the TIUS. Truck activity per dollar of GNP for the 1982 and 1987 TIUS is shown in Figure 14 in terms of ton-miles and vehicle miles. According to the TIUS, there was about 0.3 ton-miles/dollar, with a slight decline over the five year period. In contrast, vehicle miles per dollar of output increased slightly, implying an overall decline in load factors (ton-miles/vehicle-mile). When the data are broken down by length of haul, a slightly different pattern emerges. Ton-miles per dollar declined for local movements but increased slightly for long-haul movements. Again, short haul movements appear to be intermediate between the two, showing a smaller decline than local traffic. Local truck vehicle miles per dollar of GNP is virtually constant at 0.0083 in both years (Table 1). Declining load factors for local trucks could be due to any or all of three factors: 1) decreasing densities of commodities, 2) decreasing proportion of local truck movements that are commodity shipments (more service activity and less delivery), and 3) decreasing efficiency of truck utilization (more partial loads and empty backhauls). The apparent decline in average loads for local trucks from 1982 to 1987 was quite pronounced: a $25 \%$ decline from 8.7 to 6.5 tons per truck (Figure 15). With ton-miles per GNP declining at an average rate of about $5 \% / y r$. and load factors also decreasing at $5 \% /$ yr., vehicle miles per dollar of GNP remained constant.

${ }^{10}$ The TIUS, virtually the only source of consistent estimates of ton-miles by all types of trucks, classify vehicles by three ranges of operation: 1) local, 2) over-the-road less than 150 miles, and 3) long-haul over 150 miles. TIUS ton-mile estimates are available for only 1982 and 1987, however.

${ }^{11}$ This may be ton-miles by all modes of transport or combined truck and rail ton-miles. An illustration is given below. 
Figure 13.

TRUCK FREIGHT MODEL STRUCTURE

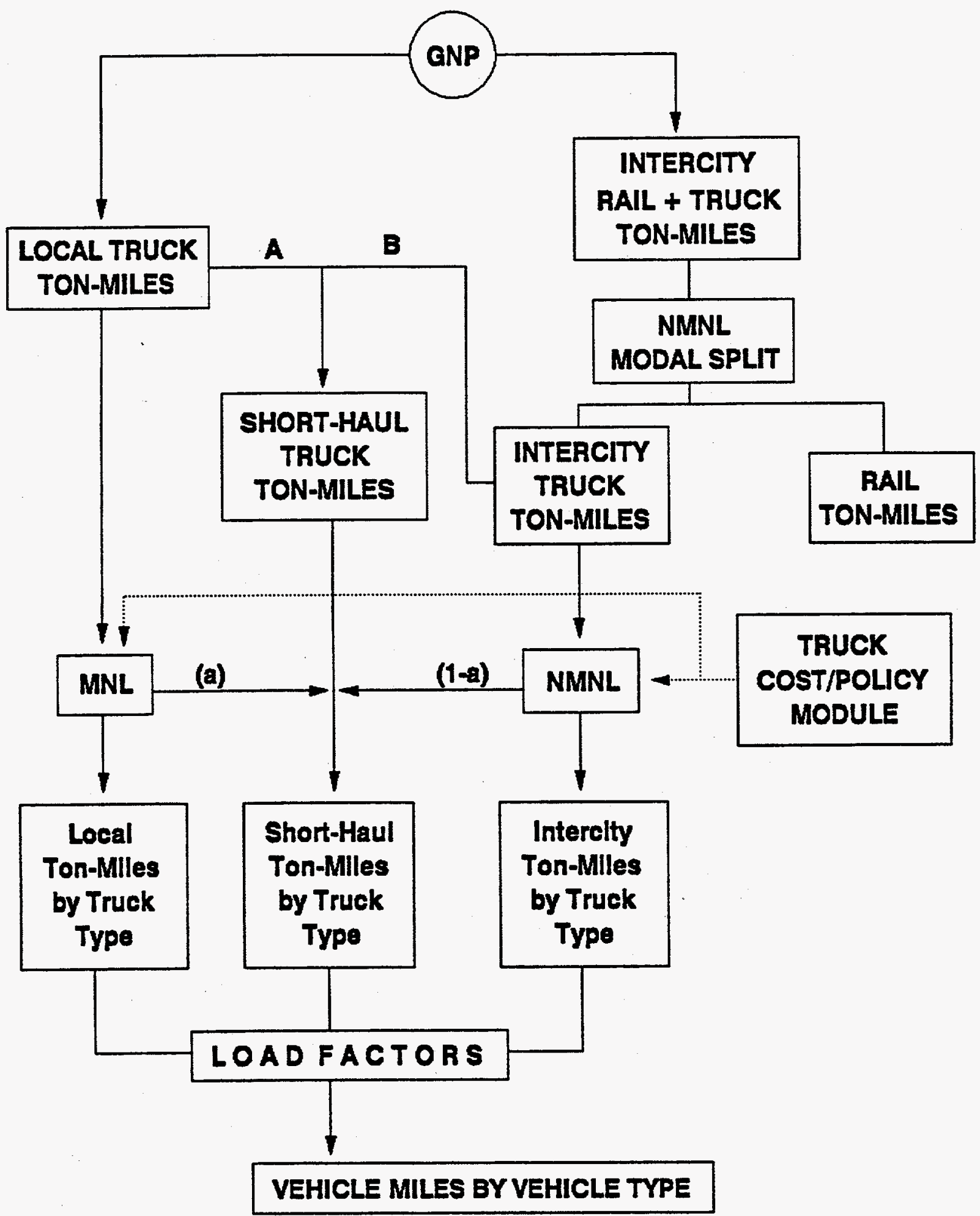


Figure 14.

\section{TRUCK ACTIVITY PER DOLLAR OF GNP}

By Length of Haul

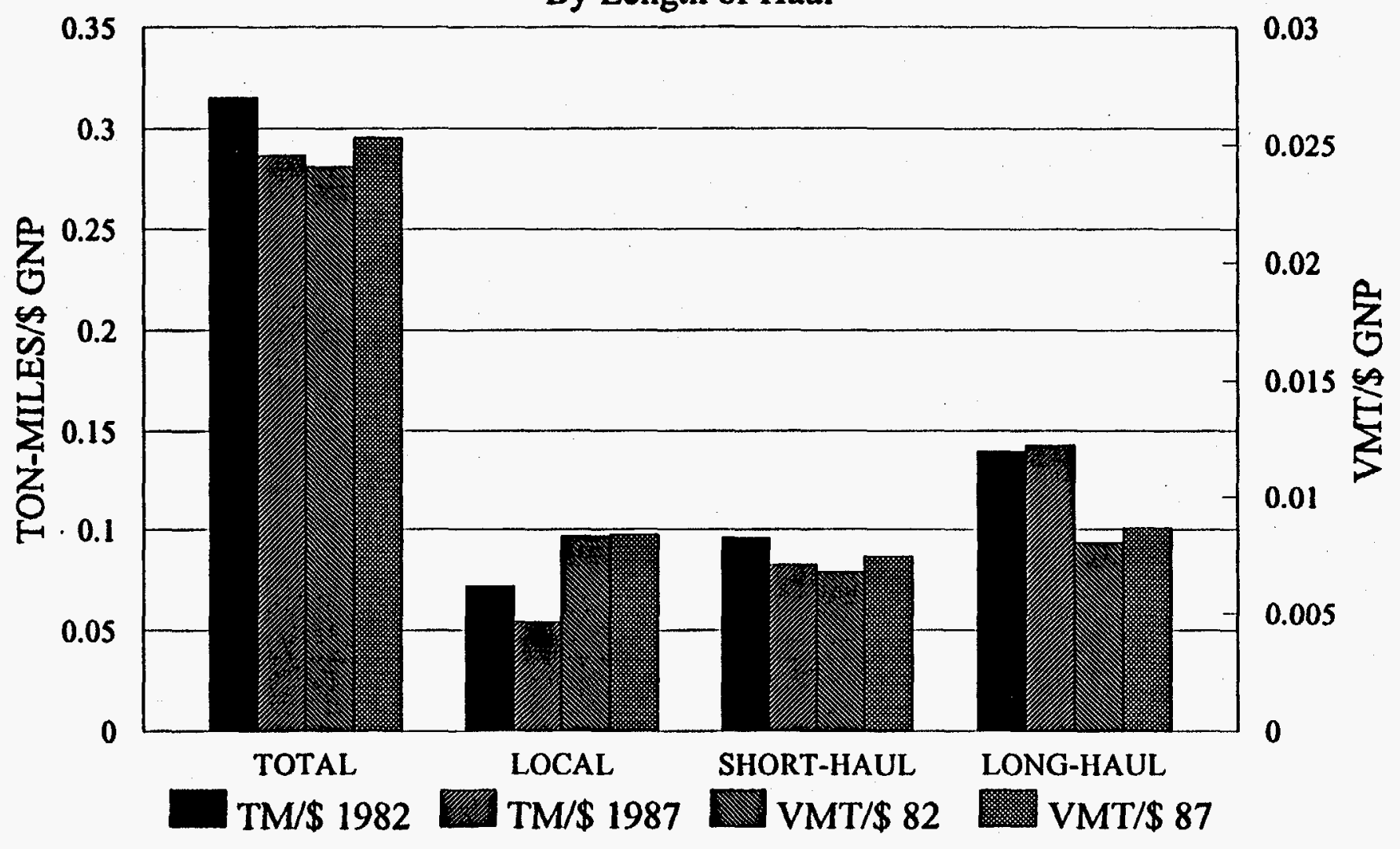


Figure 15.

TRUCK LOAD FACTORS, 1982 v. 1987

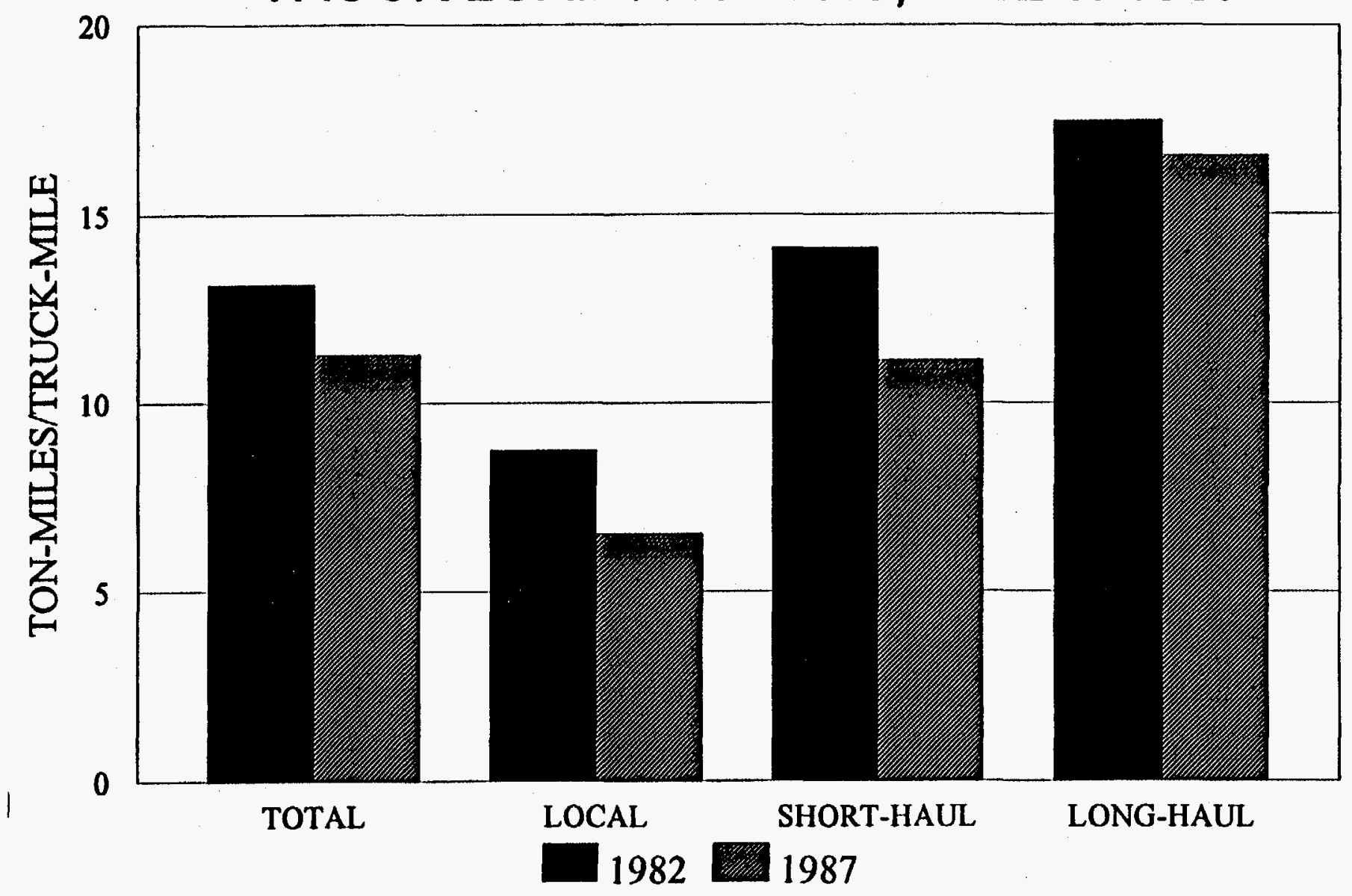


Table 1. Local Ton-Miles and Vehicle Miles Relative to GNP and Intercity Miles

\begin{tabular}{lcc}
\hline & 1982 & 1987 \\
\hline Local Truck VMT (billions) & 26.2 & 32.0 \\
Local Truck TM (billions) & 229.0 & 208.5 \\
GNP (1982 \$) & 3166.0 & 3845.3 \\
Short-Haul TM (<150 mi.) & 302.8 & 318.3 \\
Intercity Ton-Miles & 442.1 & 548.9 \\
Local VMT/\$GNP & 0.0083 & 0.0083 \\
Local TM/\$GNP & 0.0723 & 0.0542 \\
Local Load Factor (TM/VM) & 8.7 & 6.5 \\
Local Share of Total VMT & $34.5 \%$ & $32.9 \%$ \\
Local Share of Total TM & $22.9 \%$ & $19.0 \%$ \\
\hline
\end{tabular}

There is no clearly best way to predict local truck ton-miles or VMT based on these two years' statistics. To make matters more confusing, the data indicate substantial but offsetting trends in load factors and ton-miles per dollar of output for local trucks. It is not reasonable to assume that such trends can continue indefinitely.

In keeping with the philosophy of the long-run forecasting model as a scenario-building tool, we require the analyst to specify trends for two parameters on which the local truck forecasts will be based: 1) vehicle miles per dollar of GNP (V\$) and the annual rate of change in VMT/\$ ( $\phi)$, and 2) average ton-miles per vehicle mile $(l)$ and an average annual rate of change in load factor $(\lambda)$. The forecasting equations are then,

$$
\begin{gathered}
(V M T)_{t}=(G N P)_{t}(V \$) e^{\phi t} \\
(L F)_{t}=l e^{\lambda t} \\
(T M)_{t}=(V M T)_{t}(L F)_{t}
\end{gathered}
$$

where $t$ indexes the forecast years. Obviously, this places an emphasis on understanding trends in load factors, about which little is presently known. The 1992 TIUS, about to be released, and the upcoming Commodity Flow Survey (CFS), should shed light on the question of load factor trends.

Heavy truck ton-miles as a share of total intercity ton-miles can be computed from the Smith and Wilson (1993) estimates. Next, total truck ton-miles are shared to truck types by means of a multinomial logit equation (described below). Both vehicle miles and ton-miles shares by truck type 
can be obtained from TIUS public use tapes. The share equation will be calibrated to the most recent TIUS data, and will be a function of generalized cost by truck type, which is dependent on components of operating costs and size and weight limits for each truck type. Generalized cost is computed in the Truck Cost/Policy Module (described below). Heavy truck type load factors (initially based on TIUS data but changeable by the user) are used to translate ton-miles by truck type into vehicle-miles by truck type. The equation for vehicle-miles by truck configuration $v$, $(\mathrm{VMT})_{v}$, is as follows:

$$
(V M T)_{v}=\frac{A(G N P) \times s_{T} \times s_{v}}{(L F)_{v}}
$$

where

$A=$ total intercity ton-miles as a function of GNP,

$s_{\tau}=$ trucking's share of total ton-miles,

$s_{v}=$ configuration $v$ 's share of truck ton-miles, and

$(L F)_{v}=$ the average load factor in tons per mile for truck type $v$.

The ton-mile forecasting model is consistent with the view that the economy is "dematerializing" over time, i.e., that the composition of GNP is shifting away from goods and increasingly towards services and information. The quantity of intercity freight movements is only poorly known. A consistent times series, at least, is available (Smith and Wilson, 1993). The following regression model was fitted to data covering the period 1950 to 1992 . Both GNP coefficients are easily significant at the 0.95 level.

$$
\begin{gathered}
A_{t}=-187.7+(0.847-0.00542[t-1949]) G N P_{t} \\
R \text { squared }=0.97 \quad N=31
\end{gathered}
$$

$A_{t}$ is in billions of ton-miles of intercity freight and $G_{N P}$ is in billions of constant 1987 dollars. The equation differs from a simple linear model in that ton-miles generated per dollar of GNP declines over time (Figure 16). Whereas in 1949, the model predicts 847 ton-miles per additional thousand (1987) dollars of GNP, by the year 2013 the equation will predict only 500 ton-miles of intercity movements per thousand dollars. To allow greater flexibility in constructing scenarios, the intercity ton-mile equation has been restructured to allow the user to specify an annual rate of 
Figure 16. Intercity Ton-Miles, Time Trend in Ton-Miles / $1987 \$$ of GNP

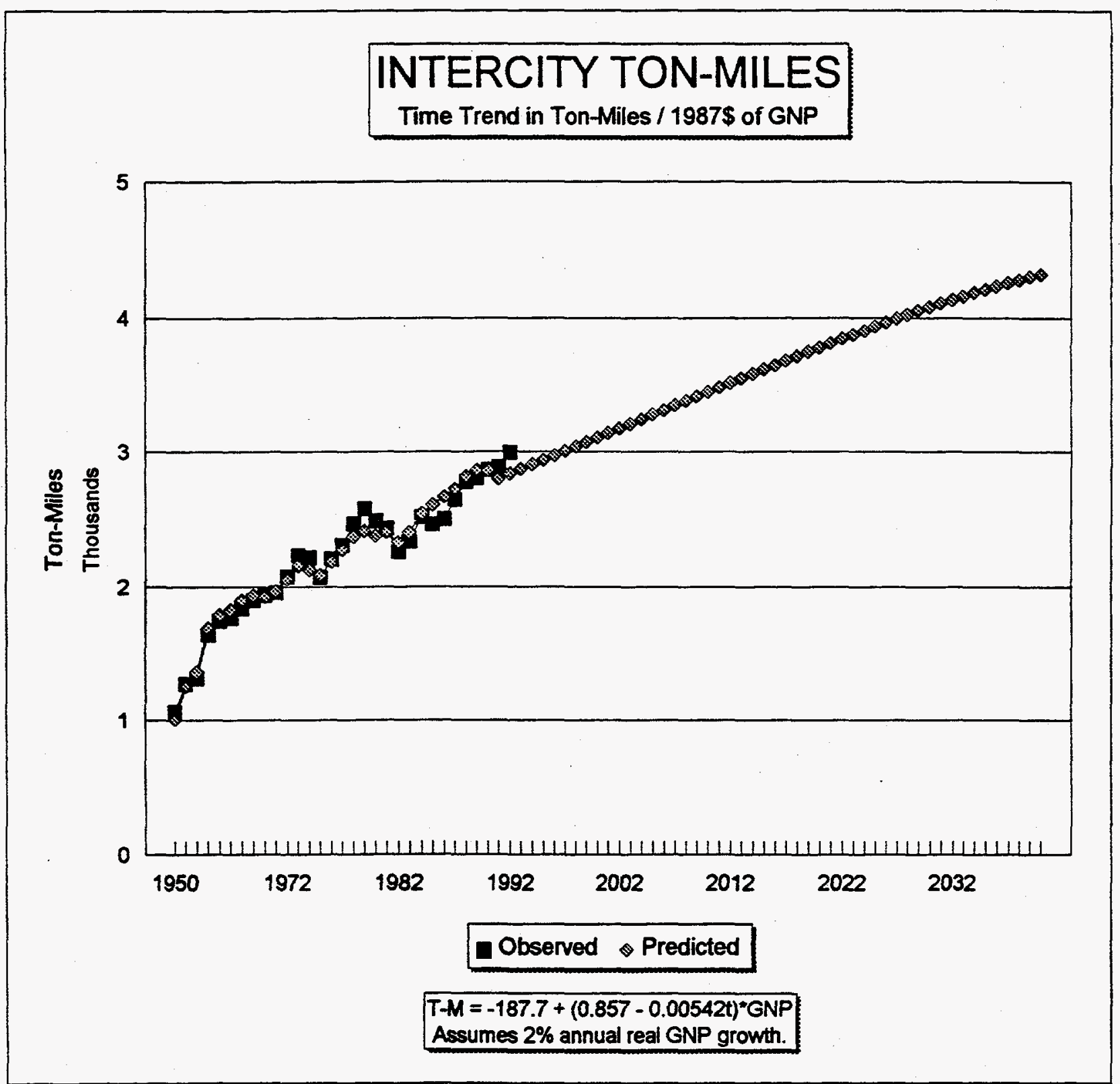


decline in ton-miles per dollar of GNP $(\eta)$. The 1992 value for the coefficient of GNP in equation $(6.5)$ is used as a starting value. The new forecasting equation is,

$$
t=-187.7+\left(0.614 e^{\eta t}\right) G N P
$$

Load factors will be assumed constant at the base year value, unless the analyst specifies a trend. The key issue in predicting truck vehicle miles is therefore the prediction of ton-mile shares. A nested multinomial logit model represents the choice of mode and vehicle type.

\subsection{LOCAL TRUCK ACTIVITY}

The compositions of local and intercity truck traffic by vehicle type are distinctly different and so two separate models of vehicle type shares represent these two markets. Long-haul traffic is dominated by single trailer combination vehicles, both in terms of ton-miles and vehicle miles (Figures 17-20). Most local truck vehicle miles are by single unit trucks, with the lighter trucks being the most common. Ton-miles are almost evenly divided between single unit and combination vehicles. Vehicle type distributions for short-haul traffic appear to be intermediate between the local and intercity extremes, a fact that is exploited below in the estimation of short-haul truck miles.

Local truck ton-miles are distributed among truck types by means of a multinomial logit model, in which vehicle type shares are a function of the "generalized cost" of each truck type. The generalized cost includes all factors involved in the choice of vehicle type, not just the financial cost. The Truck Cost/Policy Module provides estimates of the financial cost per mile of truck operation $\left(c_{j}\right)$. For the present, we assume that other components of generalized cost will not be changed in a model run, and therefore can be represented by a vehicle-type constant term $\left(\mathrm{K}_{\mathrm{j}}\right)$. The model requires one parameter $(\gamma)$ which determines the sensitivity of vehicle type choice to generalized cost. The local truck vehicle type shares model is then,

$$
s_{j}=\frac{e^{\gamma\left(\frac{K_{j}}{\gamma}+c_{j}\right)}}{\sum_{k=1}^{n} e^{\gamma\left(\frac{K_{k}}{\gamma}+c_{k}\right)}}
$$

Calibration of the local truck shares model requires a set of initial shares and initial financial costs per mile, plus an estimate of the financial cost-per-mile elasticity of one of the base shares. The 
Figure 17.

Distribution of Ton-Miles, 1982 By Truck Type and Length of Haul

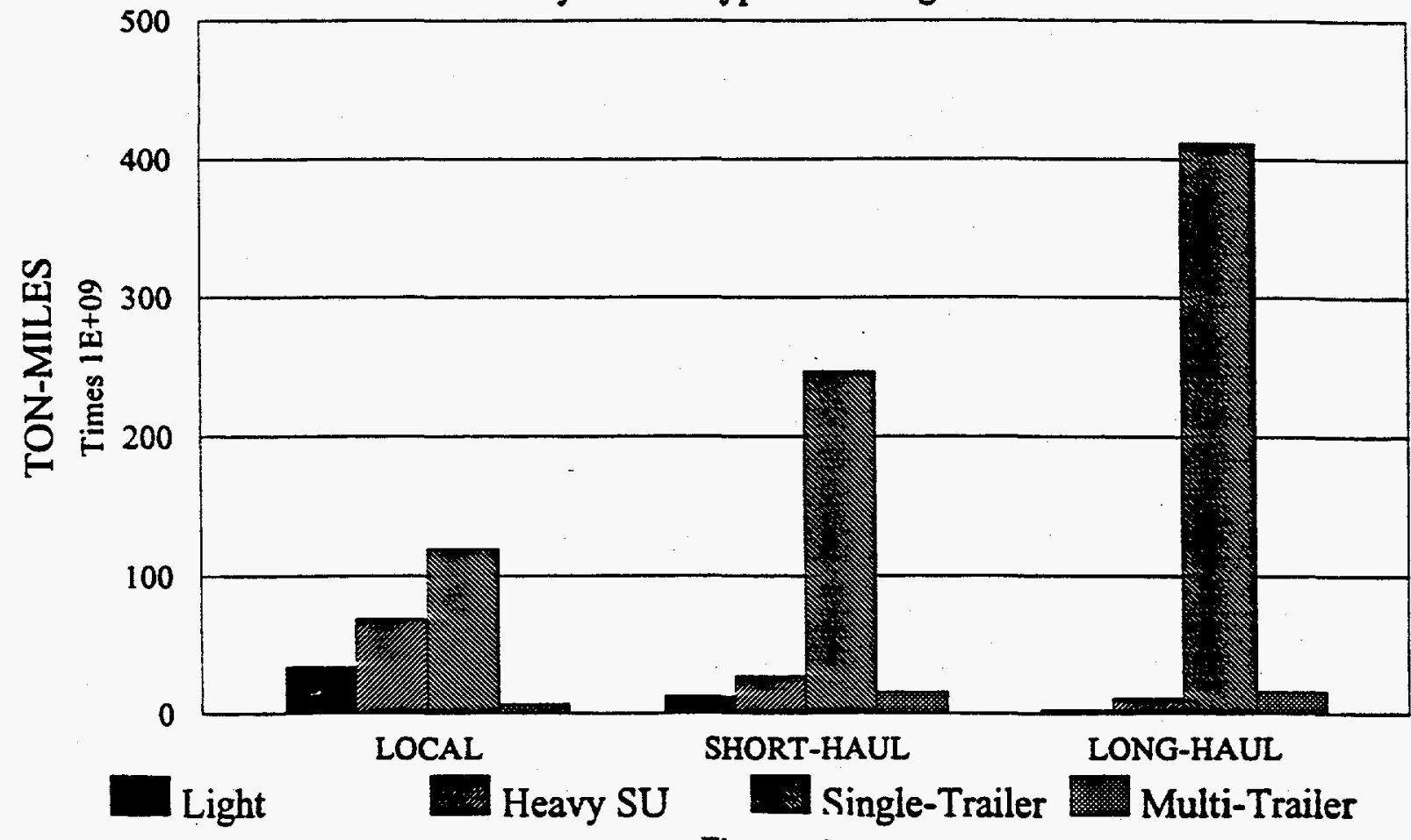

Figure 18.

Distribution of Ton-Miles, 1987 By Truck Type and Length of Haul

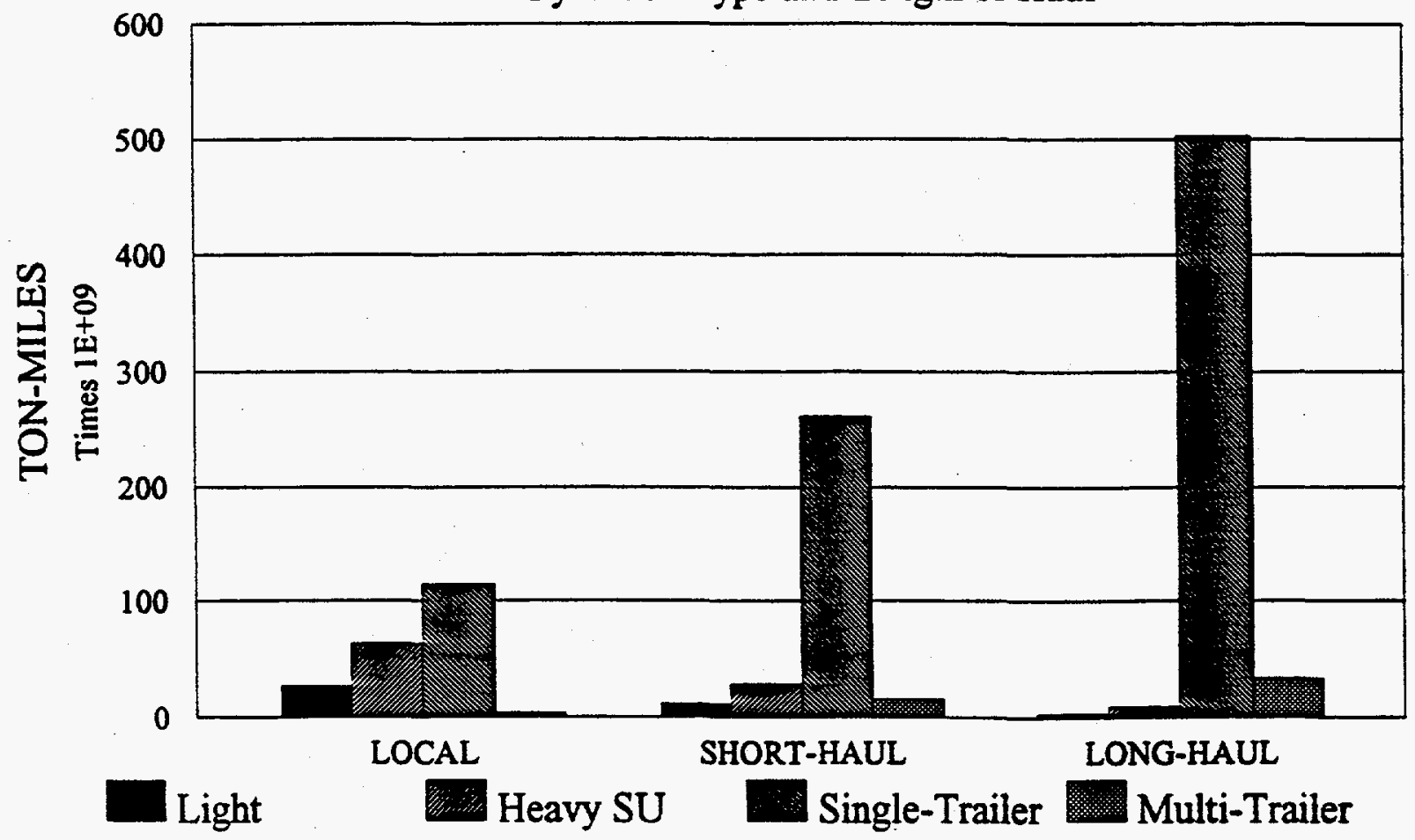


Figure 19.

Distribution of Vehicle-Miles, 1982 By Truck Type and Length of Haul

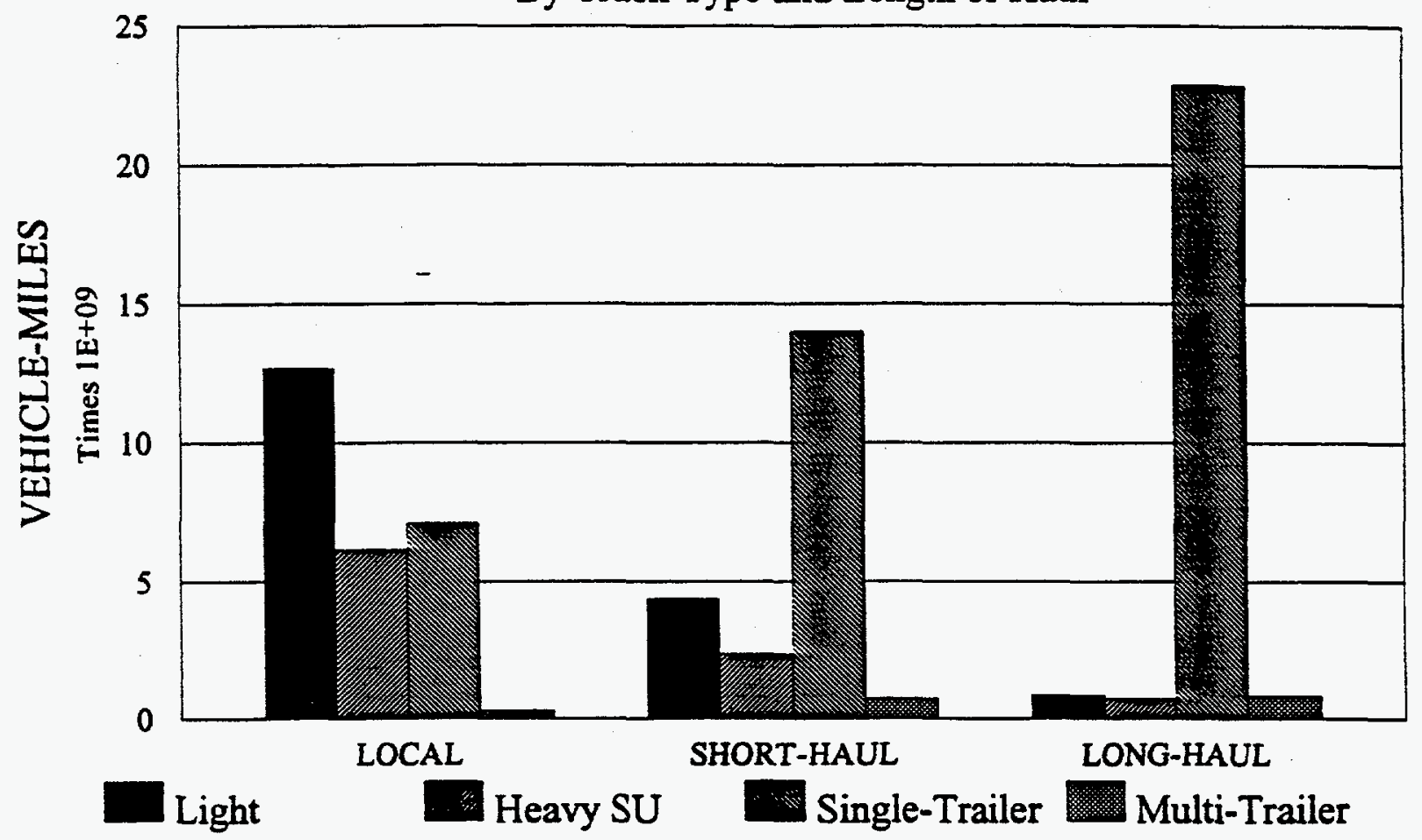

Figure 20.

Distribution of Vehicle-Miles, 1987 By Truck Type and Length of Haul

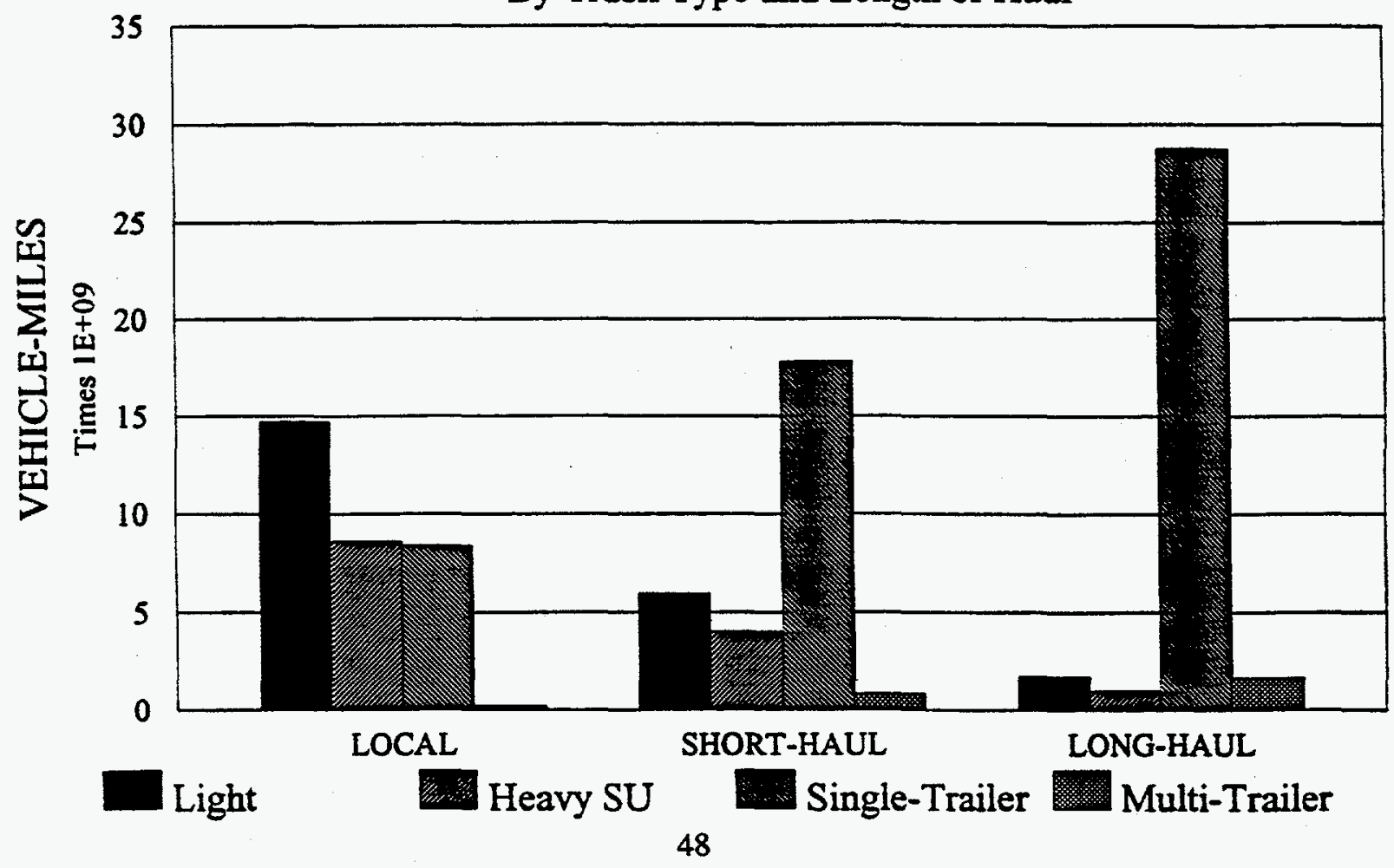


generalized cost sensitivity parameter, $\gamma$, can be computed from the definition of elasticity in the MNL model.

$$
\begin{gathered}
\eta=\gamma\left(1-s_{i}\right) c_{i} \\
\gamma=\frac{\eta}{\left(1-s_{i}\right)} c_{i}
\end{gathered}
$$

Vehicle type constants can then be computed by using the fact that the log of the ratio of shares is a linear function of the constants, $\mathrm{K}$, and the cost-per-mile differences.

$$
\ln \left(\frac{s_{i}}{s_{0}}\right)=K_{i}-K_{0}-\gamma\left(c_{i}-c_{0}\right)
$$

Since adding a constant to the generalized costs of all truck types will not change the shares, we can set $\mathrm{K}_{\mathrm{o}}=0$, and solve for $\mathrm{K}_{\mathrm{i}}$.

$$
K_{i}=\ln \left(\frac{s_{i}}{s_{o}}\right)-\gamma\left(c_{i}-c_{o}\right)
$$

\subsection{INTERCITY TRUCK ACTIVITY}

The modal distribution of intercity freight traffic is better represented by a nested multinomial logit model. The probability of choosing mode I (truck or rail) and submode $\mathrm{j}$ (truck configuration) or, alternatively, the market share of mode $I$ and submode $j, s_{i j}$ can always be written as a product of the conditional probability of choosing submode $j$ given that mode $I$ has been chosen, $s_{j \mid l}$, and the marginal probability of choosing mode $I, s_{i}$.

$$
s_{i j}=s_{j \mid i} s_{i}
$$

We assume that choice of vehicle configuration within the trucking mode follows the multinomial logit model, based on a measure of generalized cost, $c_{i j}$, with constant terms $\alpha_{i}$, and cost sensitivity coefficient $\mu_{\mathrm{i}}$. The conditional probability of choice of submode $\mathrm{j}$, given mode $\mathrm{I}$, is then, 


$$
s_{j \mid i}=\frac{e^{\mu_{i}\left(\frac{\alpha_{i j}}{\mu_{j}}+c_{i j}\right)}}{\sum_{k=1}^{n_{i}} e^{\mu_{i}\left(\frac{\alpha_{i k}}{\mu_{i}}+c_{i k}\right)}}
$$

We assume that the choice of mode also follows the multinomial logit model and also depends on the generalized cost of mode I and a cost-sensitivity parameter, $\beta$. The generalized cost of mode I includes the average generalized cost of the submodes that make up mode I, plus some common modal costs. In the multinomial logit framework, the average submodal cost is not simply a weighted average of the submodal costs. As Williams (1974) showed, the average cost is given by,

$$
\overline{c_{i}}=\frac{1}{\mu_{i}} \ln \left(\sum_{j=1}^{n_{i}} e^{\mu_{i}\left(\frac{\alpha_{j}}{\mu_{i}}+c_{i j}\right)}\right)+X
$$

where the constant $\mathrm{X}$ can be omitted since it has no effect on the choice probabilities (Fisk and Boyce, 1984). The generalized cost of mode $I$ is the sum of the average cost and modal costs, $u_{i}$, including modal constant terms, $\boldsymbol{k}_{i}$. The probability of choice of mode $I$ is thus,

$$
s_{i}=\frac{e^{\beta\left(\frac{x_{i}}{\beta}+u_{i}+\overline{c_{i}}\right)}}{\sum_{k=1}^{M} e^{\beta\left(\frac{K_{k}}{\beta}+u_{k}+\overline{c_{k}}\right)}}
$$

where $M$ is the number of modes.

Note that the price sensitivity parameters are different for choice of submode $\left(\mu_{\mathrm{i}}\right)$ and choice of mode $(\beta){ }^{12}$ If they were the same, the choice model would be a simple multinomial logit model, the choice set being all submodes of all modes, treated equally. In fact, a requirement of the NMNL

${ }^{12}$ The generalized cost parameter is also the parameter of the extreme value distribution which gives rise to the MNL functional form. The larger the cost sensitivity, the smaller the variance of the error terms or unobserved attributes. Intuitively, this means, the less important unobserved (noncost) attributes are in the choice decision, the more sensitive the decision will be to costs. It seems reasonable to assume that the unobserved attributes (speed, reliability, etc.) in the choice of truck configuration would be less important than those in the choice between rail and truck. 
model is that $\mu_{\mathrm{i}}>\beta$, for all $\mathrm{I}$. That is, the choice among submodes must be more price sensitive than the choice of mode. Unless this holds true, the NMNL model is inappropriate. Intuitively, it seems reasonable that choice of truck type would be more sensitive to cost than choice of mode, since the service is likely to be more similar in other, non-financial respects.

It seems reasonable to assert that truck and rail do not compete head to head for every ton-mile of intercity freight. For example, rail competes with barge for long-haul energy and mineral resource movements, and trucks are not a consideration (to a close approximation). Rail does not compete with truck for small, short-distance delivery. The segmentation of the ton-mile market can be approximated in the NMNL model. However, the analyst must specify the fraction of intercity tonmiles which will never be captured by truck, as well as the fraction that will always be captured by truck. The NMNL model will then apply to the remaining fraction. Competition among truck modes will apply to the sum of the truck-only ton-miles plus the truck share of ton-miles for which the modes compete. Note that this puts the burden on the analyst to insure that the price sensitivity is consistent with the assumed market segmentation. Price sensitivity would be lowest if no segmentation were assumed and greater if the modes were allowed to compete for only a small fraction of the ton-miles. In other words, lack of competition over a larger fraction of ton-miles can be approximated by assuming that modal shares are relatively insensitive to costs.

Calibration of the NMNL mode and submode choice models is straightforward. First, the analyst must supply a set of initial ton-mile shares, such that the modal shares sum to 1.0, and the submodal shares also sum to 1.0. This can be based on the TIUS, the CFS, etc. Second, elasticities of shares with respect to generalized cost must be specified for one of the modes and one of the submodes, at the initial market share. In the MNL model, the market share elasticity of price is related to the initial share, the initial cost, and the cost sensitivity parameters, as follows.

$$
\eta_{i, c_{i}}=\frac{\partial s_{i}}{\partial c_{i}} \cdot \frac{c_{i}}{s_{i}}=\beta c_{i}\left(1-s_{i}\right) \Rightarrow \beta=\frac{\eta_{i, c_{i}}}{c_{i}\left(1-s_{i}\right)}
$$

Initial generalized cost estimates are taken from the modal cost module, described below. An analogous equation holds for computing $\mu$, the cost sensitivity parameter of the truck configuration choice model. The elasticities must be chosen such that $\mu>\beta$ for the NMNL structure to be appropriate.

Given the price sensitivity coefficient, $\mu$, the next step is to estimate constant terms, $\alpha_{i y}$ for the vehicle configuration choice model. Once again, adding a constant term to the generalized cost of all vehicle types will not change the ton-mile shares, so that we can arbitrarily choose one vehicle 
type (say type 1) and set its constant term to zero. As in the local truck shares model, it follows that the constant for the $\mathrm{i}^{\text {th }}$ truck type can be computed from the base shares and generalized costs as follows,

$$
\alpha_{i}=\alpha_{i}-\alpha_{1}=\ln \left(\frac{s_{i}}{s_{1}}\right)-\mu\left(c_{i}-c_{1}\right)
$$

The $\alpha_{i}$ are then transformed to generalized cost by division by $\mu$.

Having estimated the parameters of the nested truck-type shares model, we can now calibrate the truck/rail modal choice model. Once again, we must start with a given set of base shares at base financial costs (per ton-mile), and a corresponding modal cost elasticity estimate $(\theta)$. If the choice is bimodal (between rail and truck) and we will not be changing the costs of rail shipments, then the NMNL modal choice model can be condensed to,

$$
s_{T}=\frac{e^{\beta\left(u_{T}+\overline{c_{T}}\right)}}{e^{R}+e^{\beta\left(u_{T}+\overline{c_{T}}\right)}}=\frac{e^{K+\beta \overline{c_{T}}}}{1+e^{K+\beta \overline{\bar{c}_{T}}}}
$$

where $R$ is a constant representing all of the generalized costs of rail freight and $K$ is a constant representing the constant generalized costs of truck freight, other than those included in the average costs passed up from the truck-type choice model. From the above, it follows that $\mathrm{K}$ and beta can be obtained from the following equations.

$$
\begin{gathered}
K=\ln \left(\frac{s_{T}}{1-s_{T}}\right)-\beta \overline{c_{T}} \\
\beta=\frac{\theta}{\left(1-s_{T}\right) \overline{c_{T}}}
\end{gathered}
$$

\subsection{SHORT-HAUL TRUCKING ACTIVITY}

As noted above, short-haul trucking appears to share characteristics with both local and intercity trucking. In fact, a simple weighted average of the local and intercity distributions can be shown to fit the short-haul vehicle type distribution well. The following equations were fitted to vehicle and ton-miles distributions by minimizing the $\mathrm{X}^{2}$ of observed and estimated short-haul truck type distributions for 1982 and 1987 , simultaneously. 


$$
\begin{aligned}
& f_{T, \text { short-haul }}=0.253 \cdot f_{T, \text { local }}+(1-0.253) \cdot f_{T, \text { intercity }} \quad \text { (ton } \\
& r_{T, \text { short-haul }}^{T}=0.395 \cdot g_{T, \text { local }}+(1-0.395) \cdot g_{T, \text { intercity }} \quad \text { (vel }
\end{aligned}
$$

where $f_{T}$ is the relative frequency of truck type $T$ in terms of ton-miles carried and $g_{T}$ is the relative frequency in terms of vehicle miles. The fitted and observed distributions are compared in Figure 21 , which shows the close agreement between the two. Only the ton-mile formula is actually used in the long-term VMT model. Thus, there will be separate multinomial logit models for predicting local versus intercity vehicle type shares, and the relative frequency distribution of short-haul traffic by truck type will be determined as a weighted average of the two.

The quantity of short-haul tons is similarly predicted as a function of local and intercity ton-miles. We assume that a certain fixed fraction $(\mathrm{A} /[1+\mathrm{A}])$ of local movements have been classified in the TIUS as short-haul movements and another fixed fraction of intercity movements $(B /[1+B])$ have also been classified as long-haul movements. Short-haul ton-miles are then equal to,

$$
(T M)_{\text {short }}=A \cdot(T M)_{\text {local }}+B \cdot(T M)_{\text {long }}
$$

Given only two years of TIUS data, the constants A and B are uniquely determined. The 1982 and 1987 data indicate $\mathrm{A}=0.79$ and $\mathrm{B}=0.26$.

Thus, short-haul ton-miles by truck type $T$ are calculated by the following equation.

$$
T M_{T, \text { short }}=T M_{\text {short }}\left[0.253 \cdot f_{T, \text { local }}+0.747 \cdot f_{T, \text { intercity }}\right]
$$

Vehicle-miles are then derived by dividing by the appropriate load factor for short-haul trucks of type $T$.

$$
V M T_{T, \text { short }}=\frac{T M_{T, \text { short }}}{L F_{T, \text { short }}}
$$




\section{DISTRIBUTION OF SHORT-HAUL TON-MILES}

\section{ACTUAL VERSUS AVERAGE OF LOCAL AND LONG-HAUL}

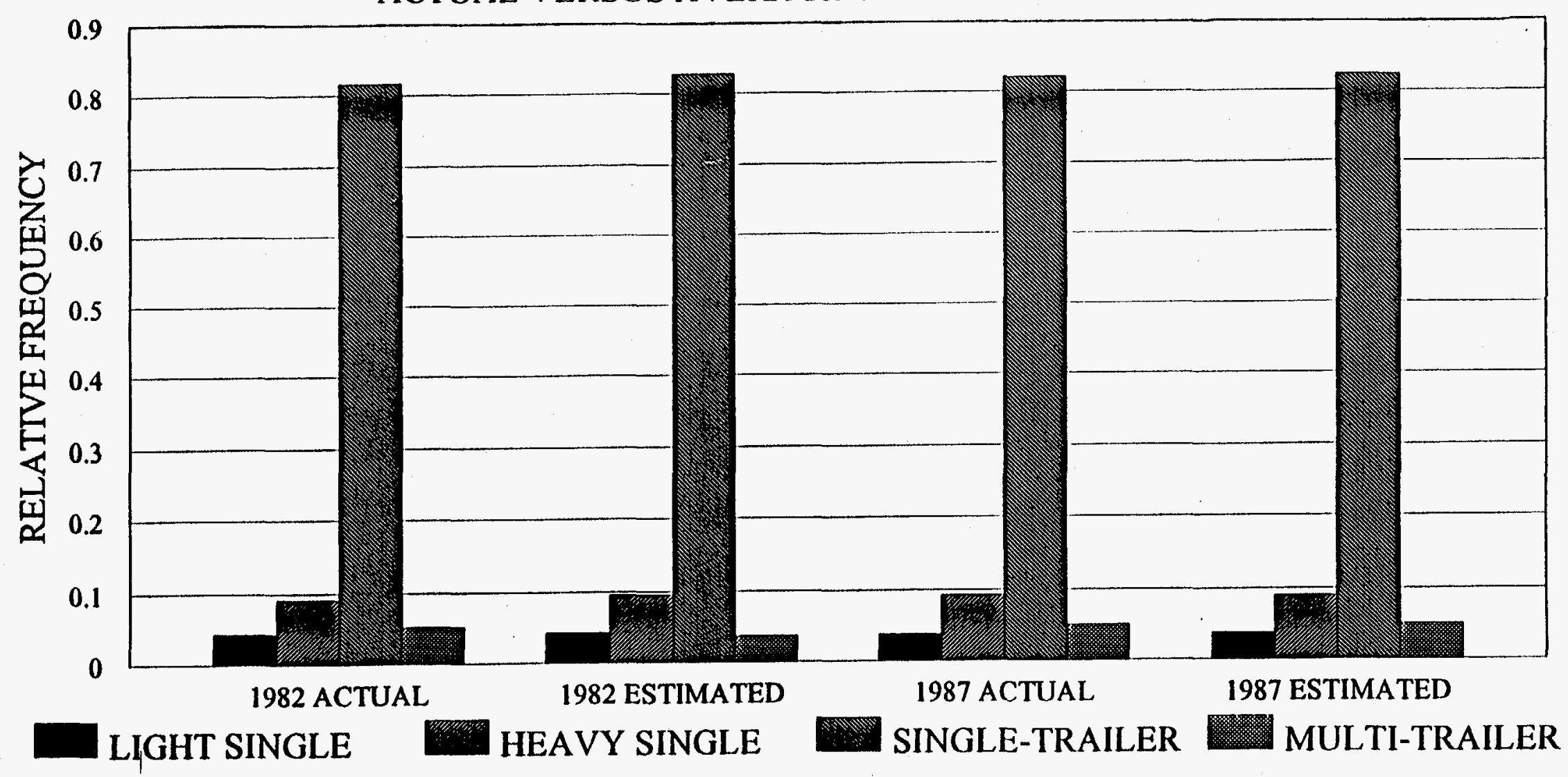




\subsection{MODAL COST ESTIMATION}

Traffic shifts resulting from changes in modal competition are based on changes in the costs and performance of the various modes. In the nested NMNL model described above, both are translated into a generalized cost measure. Therefore, a method is needed for translating policy changes, as well as trends in forecasted variables, into modal transport costs. This is the function of the Truck Cost/Policy Module. In the multinomial logit choice model, relevant modal characteristics need not be limited to per-mile financial costs but could include other measures such as speed or reliability, to the extent that they can be predicted or are policy-relevant.

The basic approach is as follows: The essence of the module is a table containing truck size (length) and weight limitations for each truck configuration. It also contains input variables necessary for computing truck unit-costs per mile (e.g., indices for labor $L$, capital $K$, fuel $F$, and maintenance $M$ costs plus weights $[\alpha, \beta, \gamma, \delta]$ for combining these into per-unit costs by configuration). (Data such as this may be found in Jack Faucett Associates and Sydec, Inc. [1990].) The user may specify taxes or surcharges on any of these variables to reflect changes in policy, economic, or technology trends. Thus, the per-unit cost index for truck type $v$ is computed by summing the weighted cost indices:

$$
c_{v}=\alpha K+\beta L+\gamma M+\delta\left(\frac{F}{M P G v}\right)
$$

where $M P G_{v}$ is specified by the analyst for the forecast year.

Size and weight changes are to be represented by converting per-unit costs into per-weight $W$ and per-volume $S$ costs by dividing by the weight limit and volume capacity of the configuration. A generalized cost index is computed as a weighted sum of the per-weight and per-volume cost:

$$
C_{v}=\frac{1}{2}\left[\left(\frac{c_{v}}{W_{v}}\right)+a\left(\frac{c_{v}}{S_{v}}\right)\right]
$$

where $a$ is a weighing factor representing the relative importance of an additional unit of volume versus an additional unit of weight.

The resulting generalized costs are used in the VMT shift model to distribute VMT among truck configurations. 



\section{SYSTEM DESIGN AND DOCUMENTATION}

\subsection{INSTALLATION}

The VMT Forecasting System is stored on three numbered diskettes. To install the system, the user should activate Windows, insert the third diskette into the disk drive, select the "Run..." option under the "File" menu in the "Program Manager" window, enter [drive:]UNSTALL.EXE, and follow the instructions on the screen. The system requires approximately 9 megabytes of hard disk space.

After the user has installed the system onto a hard disk, the user can create a new Windows program group for the system so that it will be readily available on the desktop. To create a new "Program Group," the user should select the "New..." option under the "File" menu in the "Program Manager" window. Then, while the newly created program group window is still open, the user can use the same facility to insert a new "Program Item" within the group. The user should enter [drive:] IVMTFIEXEIMANN.EXE as the command line. The system will automatically assign a Microsoft Windows default icon. The user can use the "Properties" option under the "File" menu to change the icon.

\subsection{SYSTEM REQUIREMENTS}

The system is designed to operate under the Microsoft Windows 3.0 (or higher) environment. The system is designed to use 80 percent of the user's computer memory with a minimum allocation of 1,024 kilobytes and a maximum of 4,096. The minimum memory size of 1,024 kilobytes is required by the system to load and display *.BMP files for the system's background graphics or "wallpaper." The user should note that variations in the graphics capabilities among computers may produce variations in the quality of the system's background graphics. Therefore, the user can disable the "wallpaper" function by either renaming or deleting the WALLPAPR.LOG file in the IVMTFEXE sub-directory. The system only enables the "wallpaper" capability if the WALLPAPR.LOG file is properly named and located in the proper sub-directory.

If the user experiences memory size problems, he/she can use any text editor to delete the third record (memlimit $=80,1024,4096$ ) in the CONFIG.FPW file to disable the "wallpaper" capability. 


\subsection{SYSTEM OPERATION}

Users familiar with the Microsoft Windows operating environment should be familiar with the operating conventions used by the VMT Forecasting System's user interface. However, the user should be aware of the following:

- The system allows the user to create, maintain, delete, and update multiple forecasting cases.

The system has been designed to forecast future VMT starting from 1993 to 1997. The default starting year is 1993. To generate forecasts for a year after 1993, the user must first select a starting year and enter historical data for all years between 1993 and the starting year.

- The information used to estimate the regression equations used in the short-term VMT forecasting models and vehicle sales models are provided in a Lotus 1-2-3 file (VMTDOC.WK4) in the IVMTFIWKS sub-directory. The user can use this spreadsheet to recalculate regression equations as more-current data becomes available. The system allows the user to modify coefficients as long as the model functional forms have not changed.

- The VMT Forecasting System is data intensive. Therefore, brief descriptions and source information have been provided for most items included in the databases. This information is located in "Memo" fields at the end of each database record. The user can use the mouse to double click on a "Memo" field to display a text window containing the provided information. Memo fields that contain data will have the word memo capitalized; those containing no information will have the word memo uncapitalized.

- The tractor sales model uses the combination truck VMT forecasts as input. Therefore, the user must run the short-term truck VMT model before running the tractor sales model.

- To print graphics displays, the user must type "P" or "p" on the keyboard immediately after the figure is displayed on the screen. The system will not print the figure after the user moves, resizes, minimizes, or maximizes the display window.

\subsection{OUTPUT}

The VMT Forecasting System has the capability to generate hardcopy output in both tabular and graphic form. Since the system is developed to operate under the Microsoft Windows environment, printing functions are determined by the Window environment's default printer. The user should 
select the desired printer using either the "Control Panel" or "Print Manager" within the Microsoft Windows "Main" program group. The VMT Forecasting System does not provide the capability for the user to specify a printer. 



\section{REFERENCES}

1. Apogee Research, Inc. 1990. The Highway Revenue Forecasting Model. Report prepared for the Office of Policy Development, Federal Highway Administration, U. S. Department of Transportation, Washington, DC, September 18.

2. Davis, S. C. and P. S. Hu. 1991. Transportation Energy Data Book. 11 th ed. ORNL-6649, Center for Transportation Analysis, Oak Ridge National Laboratory, Oak Ridge, Tennessee, January.

3. Energy Information Administration. 1990. Household Vehicles Energy Consumption 1988. DOE/EIA-0464(88). U. S. Department of Energy, Washington, DC, February.

4. Energy Information Administration. 1990. PC-AEO Forecasting Model for the Annual Energy Outlook 1990. DOE/EIA-M036(90). Office of Integrated Analysis and Forecasting, Washington, DC.

5. Engle, R. F. and C. W. J. Granger. 1987. Co-integration and Error Correction: Representation, Estimation, and Testing. Econometrica 55-2: 251-276.

6. Federal Highway Administration, Office of Highway Information Management. 1991. Highway Statistics 1991. U. S. Department of Transportation, Washington, DC.

7. Federal Highway Administration. 1987(b). Trends and Forecasts of Highway Freight Travel. Working Paper 3. The Future National Highway Program: 1991 and Beyond. Washington, DC, April.

8. Federal Highway Administration. 1987(a). Trends and Forecasts of Highway Passenger Travel. Working Paper 2. The Future National Highway Program: 1991 and Beyond. Washington, DC, October.

9. Fisk, C. S., and D. Boyce. 1984. "A Modified Composite Cost Measure for Probabilistic Choice Modeling," Environment and Planning A, vol. 16, pp. 241-248.

10. Friesz, T. L., and R. L. Tobin, eds. 1983. Intercity Freight Modeling. Transportation Research Special Issue, 17A;6, November.

11. Gately, D. 1990. The U. S. Demand for Highway Travel and Motor Fuel. The Energy Journal 11;3:59-73.

12. Golob, T. F., M. J. Beckmann, and Y. Zahavi. 1981. A Utility-Theory Travel Demand Model Incorporating Travel Budgets. Transportation Research B 15B;6:375-389. 
13. Greene, D. L. 1994. Alternative Fuels and Vehicles Choice Model, ORNL/TM-12738, Center for Transportation Analysis, Oak Ridge National Laboratory, Oak Ridge, TN, October.

14. Greene, D. L. 1992. Vehicle Use and Fuel Economy: How Big is the Rebound Effect? The Energy Journal 13;1:117-143.

15. Greene, D. L., and A. Rathi. 1990. Alternative Motor fuel Use Model: Model Theory and Design and User's Guide. ORNL/TM-11448, Center for Transportation Analysis, Oak Ridge National Laboratory, Oak Ridge, TN, March.

16. Greene, D. L. 1987. Long-Run Vehicle Travel Prediction From Demographic Trends. Paper presented at the $66^{\text {th }}$ Annual Meeting, Transportation Research Board, Washington, DC, by the Center for Transportation Analysis, Oak Ridge National Laboratory, Oak Ridge, TN.

17. Greene, D. L. 1986. Parametric Forecasting of Vehicle Travel: Methodology and Accuracy. Report prepared for Federal Highway Administration, Office of Policy Development by the Center for Transportation Analysis, Oak Ridge National Laboratory, Oak Ridge, TN.

18. Greene, D. L. and J. T. Liu. 1986. Scrappage, Depreciation, and the Supply of Used Capital Stock: Highway Vehicles in the United States. Working Paper. Center for Transportation Analysis, Oak Ridge National Laboratory, Oak Ridge, TN, May.

19. Greene, D. L. 1984. A Derived Demand Model of Regional Highway Diesel Fuel Use. Transportation Research B 18B;1:43-61.

20. Greene, W. H. 1992. LIMDEP Version 6.0. Econometric Software, Inc., Bellport, NY.

21. Hu, Patricia S., and Jennifer Young. (1993). 1990 Nationwide Personal Transportation Survey Data Book: Volume I. ORNL/M-3000, U.S. Department of Transportation, Federal Highway Administration, Washington, DC.

22. Jack Faucett Associates and Sydec, Inc. 1990. The Effect of Size and Weight Limits on Truck Costs. JACKFAU-90-352-1. Bethesda, Maryland.

23. Kirby, H. R. 1981. Forward: Special Issue on Personal Travel Budgets. Transportation Research B 15B;6:375-389.

24. Kitamura, R. 1988. Life-Style and Travel Demand. A Look Ahead: Year 2020. Transportation Research Board, National Research Council, Washington, DC, pp. 149-189.

25. Lave, Charles A. 1990. Future Growth of Automobile Travel in the U.S.: A Non-Problem. Proceedings of Conference on Energy and the Environment in the 21st Century, March 26-28, 1990, Energy Laboratory, Massachusetts Institute of Technology, Cambridge, MA, pp. 227229.

26. Maring, G. 1974. Highway Travel Forecasts. Final Report. Federal Highway Administration, Office of Highway Planning, Washington, DC. 
27. Miaou, S. P. 1991. Vehicle Scrappage Model, internal memorandum, Center for Transportation Analysis, Oak Ridge National Laboratory, Oak Ridge, TN, February 12.

28. Rathi, A. K., P. DeCorla-Souza, S. P. Miaou, and F. Southworth. 1991. The Effects of Latent Demand and Travel Demand Management on Future Highway Needs. Manuscript. Center for Transportation Analysis, Oak Ridge National Laboratory, Oak Ridge, TN.

29. Mintz, M. M. and A. D. Vyas. 1991. Forecast of Transportation Energy Demand Through the Year 2010. ANL/ESD-9. Center for Transportation Research, Argonne National Laboratory, Argonne, IL, April.

30. Pisarski, A. E. 1992. Travel Behavior Issues in the 90's. U. S. Department of Transportation, Federal Highway Administration, Office of Highway Information Management, Washington, DC, July.

31. Reno, A. T. 1988. Personal Mobility in the United States. A Look Ahead: Year 2020. Transportation Research Board, National Research Council, Washington, DC, pp. 369-393.

32. Sierra Research, Inc. 1990. Review and Evaluation of Current VMT Forecasts. Report prepared for U. S. Environmental Protection Agency, Office of Mobile Sources, Ann Arbor, Michigan, by Sierra Research, Inc., Sacramento, California.

33. Smith, F. A. and R. A. Wilson. 1993. Transportation in America, $11^{\text {th }}$ Edition. Eno Transportation Foundation, Inc., Landsdowne, Virginia.

34. Southworth, F. 1986. VMT Forecasting for National Highway Planning: A Review of Existing Approaches. Report prepared for Office of Policy Development, Federal Highway Administration, U. S. Department of Transportation, by the Center for Transportation Analysis, Oak Ridge National Laboratory, Oak Ridge, TN, June.

35. Southworth, F. and J. J. Ray. 1993. Highway Traffic Forecasting System: 1993 Functional Description. Prepared for Office of Policy Development, Federal Highway Administration, Washington, DC.

36. Tanner, J. C. 1981. Expenditure of Time and Money on Travel. Transportation Research $15 \mathrm{~A} ; 1: 25-38$.

37. Weinblatt, H. 1988. The FHWA/Faucett VMT Forecasting Model. Report prepared for the Office of Policy Development, Federal Highway Administration, by Jack Faucett Associates, Bethesda, Maryland.

38. Weinblatt, H. 1989. The FHWA/Faucett VMT Forecasting Model. Report prepared for the Office of Policy Development, Federal Highway Administration, by Jack Faucett Associates, Bethesda, Maryland, February.

39. Williams, H. C. W. L. 1974. "On the Formation of Travel Demand Models and the Evaluation of User Benefit," Environmental and Planning A, vol. 9, pp. 285-344. 
40. Winston, C. 1983. The Demand for Freight Transportation: Models and Applications. Transportation Research A 17A;6:419-427. 
ORNL-6872

\section{INTERNAL DISTRIBUTION}

1-10. D. T. Bain

11. E. L. Blaylock

12. M. Bronzini

13-22. S. M. Chin

23. G. E. Courville

24. T. R. Curlee

25. S. R. Damewood

26. S. C. Davis

27. T. D. Ferguson

28. S. D. Floyd

29-33. R. Gibson

34. P. S. Gillis

35-49. D. L. Greene

50. E. Hillsman

51. D. W. Jones

52. V. C. Mei

53. S. P. Miaou
54. D. P. Middendorf

55. C. I. Moser

56. A. K. Rathi

57. D. E. Reichle

58. R. B. Shelton

59. B. M. Sorensen

60. F. Southworth

61. M. Summers

62. R. K. Tallent

63. D. Trumble

64. M. Walsh

65. T. J. Wilbanks

66. ORNL Patent Office

67. Central Research Library

68. Document Reference Section

69-71. Laboratory Records

72. Laboratory Records - RC

\section{EXTERNAL DISTRIBUTION}

73. Dr. Thomas E. Drabek, Professor, Department of Sociology, University of Denver, Denver, CO 80208-0209

74. Dr. Stephen G. Hildebrand, Director, Environmental Sciences Division, Oak Ridge National Laboratory, P. O. Box 2008, Oak Ridge, TN 37831-6037

75. Mr. George F. Sowers, P.E., Senior Vice President, Law Companies Group, Inc., 114 Townpark Drive, Suite 250, Kennesaw, GA 30144-5599

76. Dr. C. Michael Walton, Ernest H. Cockrell Centennial Chair in Engineering and Chairman, Department of Civil Engineering, University of Texas at Austin, Austin, TX 78712-1076

77. Office of Assistant Manager for Energy Research and Development, DOE-ORO, P. O. Box 2001, Oak Ridge, TN 37831-8600

78-79. OSTI, U.S. Department of Energy, P. O. Box 62, Oak Ridge, TN 37831

80. Deborah Adler, U. S. Environmental Protection Agency, Fuel Studies and Standards Branch, 2565 Plymouth Road, Ann Arbor, MI 48105

81. Lana R. Batts, American Trucking Associations, 2200 Mill Road, Alexandria, VA

82. John Bert, Federal Highway Administration, Office of Policy Development, HPP-13, 400 Seventh Street, S.W., Washington, DC 20590

83. David Bunch, Management School, University of California at Davis, Davis, CA 95616

84. Harry B. Caldwell, U.S. Department of Transportation, Federal Highway Administration, 400 Seventh Street, S.W., Washington, DC 20590

85. David Chien, EI-813, Room 2F-081, U.S. Department of Energy, 1000 Independence Avenue, S.W. Washington, DC 20585 
86. Barry Cohen, EI-622, Room JH072, U.S. Department of Energy, Energy Information Administration, Forrestal Building, 1000 Independence Avenue, S.W., Washington, DC 20585

87. John DeCicco, American Council for an Energy-Efficient Economy, 1001 Connecticut Avenue, N.W., Suite 801, Washington, DC 20036

88. Mark A. DeLucchi, 3925 Main Street, Fair Oaks, CA 95628

89. Carmen Difiglio, U.S. Department of Energy, 1000 Independence Avenue, S.W. Washington, DC 20585

90. Richard Farmer, Natural Resource and Commerce Division, CBO, House Annex No. 2, Second and D Street, S.W., Washington, DC 20515

91. Christopher Fleet, Chief Planning Support Branch, Federal Highway Administration, 400 Seventh Street, S.W., (HPN-22), Washington, DC 20590

92. John W. Fuller, Urban and Regional Planning, 340 Jessup Hall, University of Iowa, Iowa City, IA 52242-1316

93. Lew Fulton, EP-50, Room 7H-021, U.S. Department of Energy, 1000 Independence Avenue, S.W. Washington, DC 20585

94. Dermot Gately, New York University, Economics Department, New York, NY 10003

95. Deborah Gordon, Climate Change and Energy Program, Union of Concerned Scientists, 1616 P Street, N.W., Suite 310, Washington, DC 20036

96. David A. Hensher, Institute of Transport Studies, Graduate School of Business C37, The University of Sydney, 144 Burren Street, Newtown NSW 2006, Australia

97. Arthur Jacoby, Federal Highway Administration, HPP-10, 400 Seventh Street, S.W., Washington, DC 20590

98. Ed Kashuba, HPM-30, Room 3300, Federal Highway Administration, 400 Seventh Street, S.W., Washington, DC 20590

99. J. Daniel Khazzoom, School of Business, San Jose State University, One Washington Square, San Jose, CA 95192-0069

100. Ryuchi Kitamura, Department of Civil Engineering, University of California, Davis, CA 95616

101. T. R. Lakshmanan, Bureau of Transportation Statistics, (BTS-10), U. S. Department of Transportation, 400 Seventh Street, S.W., Washington, DC 20590

102. Charles A. Lave, University of California, Economics Department, Institute of Transportation Studies, Irvine, CA 92717

103. John Maples, 2331 Putnam Lane, Crofton, MD 21114

104. Jim March, Office of Policy Development, FHWA, HPP-12, 400 Seventh Street, S.W., Washington, DC 20590

105. Gary Maring, Office of Policy HPP-10, Federal Highway Administration, 400 Seventh Street, S.W., Washington, DC 20590

106. Dave McElhaney, HPM-1, Federal Highway Administration, 400 Seventh Street, S.W., Washington, DC 20590

107. Barry McNutt, EP-50, Room 7H-021, U.S. Department of Energy, 1000 Independence Avenue, S.W. Washington, DC 20585

108. Marianne Millar Mintz, Argonne National Laboratory, 9700 S Cass Avenue, Building 362, MS-2B, Argonne, IL 60439

109. Phil Patterson, CE-30, Room 6B-094, U.S. Department of Energy, 1000 Independence Avenue, S.W. Washington, DC 20585

110. Don H. Pickrell, U. S. Department of Transportation, Kendall Square, Cambridge, MA 02142

111. Alan E. Pisarski, 6501 Waterway Drive, Falls Church, VA 22044 
112. Roy A. Roseberry, U. S. Department of Transportation, Federal Highway Administration, Revenue Analysis BR, Washington, DC 20590

113. Rolf Schmitt, Federal Highway Administration, Room 3324, 400 Seventh Street, S.W., Washington, DC 20590

114. Will Schroeer, Environmental Protection Agency, PM-221, 401 M Street, S.W., Washington, DC 20460

115. Paul Svercl, HPM-20, Federal Highway Administration, 400 Seventh Street, S.W., Washington, DC 20590 